\title{
Visual Features in Alzheimer's Disease: From Basic Mechanisms to Clinical Overview
}

\author{
María Alejandra Cerquera-Jaramillo, ${ }^{1}$ Mauricio O. Nava-Mesa, ${ }^{2}$ \\ Rodrigo E. González-Reyes $\mathbb{D}^{2},{ }^{2}$ Carlos Tellez-Conti, ${ }^{1}$ and Alejandra de-la-Torre $\mathbb{D}^{2}$ \\ ${ }^{1}$ Escuela Superior de Oftalmología-Instituto Barraquer de América, Bogotá, Colombia \\ ${ }^{2}$ Grupo de Investigación en Neurociencias (NeURos), Escuela de Medicina y Ciencias de la Salud, Universidad del Rosario, \\ Bogotá, Colombia
}

Correspondence should be addressed to Alejandra de-la-Torre; alejadelatorre@yahoo.com

Received 21 February 2018; Accepted 7 August 2018; Published 14 October 2018

Academic Editor: Diego Sepulveda-Falla

Copyright @ 2018 María Alejandra Cerquera-Jaramillo et al. This is an open access article distributed under the Creative Commons Attribution License, which permits unrestricted use, distribution, and reproduction in any medium, provided the original work is properly cited.

\begin{abstract}
Alzheimer's disease (AD) is the leading cause of dementia worldwide. It compromises patients' daily activities owing to progressive cognitive deterioration, which has elevated direct and indirect costs. Although AD has several risk factors, aging is considered the most important. Unfortunately, clinical diagnosis is usually performed at an advanced disease stage when dementia is established, making implementation of successful therapeutic interventions difficult. Current biomarkers tend to be expensive, insufficient, or invasive, raising the need for novel, improved tools aimed at early disease detection. AD is characterized by brain atrophy due to neuronal and synaptic loss, extracellular amyloid plaques composed of amyloid-beta peptide (A $\beta)$, and neurofibrillary tangles of hyperphosphorylated tau protein. The visual system and central nervous system share many functional components. Thus, it is plausible that damage induced by $\mathrm{A} \beta$, tau, and neuroinflammation may be observed in visual components such as the retina, even at an early disease stage. This underscores the importance of implementing ophthalmological examinations, less invasive and expensive than other biomarkers, as useful measures to assess disease progression and severity in individuals with or at risk of $\mathrm{AD}$. Here, we review functional and morphological changes of the retina and visual pathway in AD from pathophysiological and clinical perspectives.
\end{abstract}

\section{Introduction}

Alzheimer's disease $(\mathrm{AD})$ is the most prevalent progressive neurodegenerative disease in humans and the main cause of dementia worldwide [1]. Together with vascular dementia, $\mathrm{AD}$ corresponds to $60 \%-80 \%$ of all dementia cases [2]. According to the World Alzheimer Report [3], an estimated 47 million people worldwide currently have dementia, a number that is projected to rise to approximately 131 million by 2050 . Several modifiable and nonmodifiable risk factors have been described for $\mathrm{AD}$, although aging remains the most significant [4]. Consequently, after 65 years of age, $\mathrm{AD}$ prevalence is expected to double every 5 years [5]. According to the US National Institute on AgingAlzheimer's Association workgroup, there are three different stages of $\mathrm{AD}$ : preclinical $\mathrm{AD}$ (presymptomatic with early
AD-related brain changes observed by neuroimaging or other biomarker studies such as amyloid and tau studies in cerebrospinal fluid (CSF)), mild cognitive impairment (MCI) caused by $\mathrm{AD}$ (mild cognitive decline but still able to perform daily activities), and dementia caused by $\mathrm{AD}$ (major cognitive decline that interferes with daily activities) [6]. Globally, AD has significant direct and indirect costs, which increased from US\$ 604 billion in 2010 to US\$ 818 billion in 2015, totaling around $1 \%$ of the worldwide gross domestic product (GDP) [3].

Two types of $A D$ have been characterized based on age of onset: early-onset $\mathrm{AD}$ (EOAD), referred to as familial, and late-onset $\mathrm{AD}$ (LOAD), which is regarded as sporadic. EOAD presents before the age of 65 and corresponds to around $5 \%$ of $\mathrm{AD}$ cases [7], while $\mathrm{LOAD}$ appears after 65 years of age and represents the most common type of 
$\mathrm{AD}$, accounting for $>90 \%$ of $\mathrm{AD}$ cases [8]. No direct cause has been described for LOAD, but its disease development is influenced by various environmental and genetic risk factors [9]. The main risk factors include aging, genetics (presenilin 1 (PSEN1), PSEN2, and APP1 genes) [7, 10], hypertension, diabetes, hypercholesterolemia, stroke, obesity, sedentary lifestyle, depression, low socioeconomic status, and alcohol and tobacco use $[1,4,9]$.

$\mathrm{AD}$ is characterized by formation and aggregation of extracellular plaques of abnormal amyloid-beta $(\mathrm{A} \beta)$ peptides, as well as presence of intracellular aggregates of hyperphosphorylated tau protein, known as neurofibrillary tangles (NFT) $[11,12]$. In $\mathrm{AD}, \mathrm{A} \beta$ peptides are produced from abnormal cleavage of the amyloid precursor protein (APP) by the beta-site amyloid precursor protein cleaving enzyme 1 (BACE-1 or $\beta$-secretase) and $\gamma$-secretase complex [13]. $\mathrm{A} \beta$ peptides promote intracellular tau phosphorylation, with hyperphosphorylated tau protein posteriorly aggregating into NFT $[11,14] . \mathrm{A} \beta$ and NFT activate astrocytes and microglia, inducing production of proinflammatory factors such as interleukins and nitric oxide (NO), and ultimately resulting in excessive neuroinflammation, oxidative stress (OS), neuronal damage, and cell death [15-17].

Currently, the diagnosis and classification of $\mathrm{AD}$ are based on clinical and neuropsychological examinations complemented by neuroimaging studies. Nonetheless, a conclusive diagnosis still relies on pathological examination of postmortem brain tissue [18]. While many exploratory biomarkers have been proposed for $\mathrm{AD}$, cerebrospinal fluid levels of tau and $\mathrm{A} \beta$ levels, together with imaging studies (such as positron emission tomography carbon 11-labeled Pittsburgh compound B), are the most widely accepted [19]. Unfortunately, these techniques are not easily accessible to patients with dementia worldwide owing to elevated costs and a lack of adequate medical facilities. Therefore, it is important to find easy-to-acquire, cost-effective methods that can provide information on the main disease manifestations, even at early stages, to favor timely interventions and improve the quality of life for patients. In this regard, a recent strategic roadmap aimed at improving early diagnosis of $\mathrm{AD}$ based on biomarkers was proposed and is centered on several phases that evaluate analytical validity, clinical validity, and clinical utility [20].

The visual system may be a helpful marker for the early stages of $\mathrm{AD}$. Brain alterations in $\mathrm{AD}$ can be accompanied by ocular symptoms [21-24] which may be related to progression, cognitive deterioration, and disease severity [25]. This may be explained because the visual system shares the same embryological origin, namely, the neural tube of the brain, and indeed is considered an extension of the diencephalon [26]. In addition, both components have several functional and structural similarities, including microvasculature and neuronal projections [27]. Furthermore, examination of the visual system may provide markers for identifying dementia subtypes, thereby helping to differentiate AD from vascular dementia [28].

Hence, the aim of this review is to describe functional and morphological changes of the eye and visual pathway that are observed in $\mathrm{AD}$ from a clinical and pathophysiological perspective. Considering that the visual system shares vascular and cellular components with the central nervous system (CNS), ocular alterations observed in patients with AD may represent an initial manifestation of the disease and serve as possible candidates for complementary diagnostic biomarkers of MCI and the early stage of $\mathrm{AD}$.

\section{Pathological Mechanisms of $\mathbf{A} \beta$ and Tau Toxicity in the Eye}

2.1. General Mechanisms of $A \beta$ and Tau Production. Senile plaques (SP) are formed from extracellular aggregation of $\mathrm{A} \beta$ deposits, which are derived from excessive or inadequate cleavage of APP by BACE- 1 and the $\gamma$-secretase complex [13]. PSEN1 and PSEN2 are part of the $\gamma$-secretase complex, which also includes nicastrin, anterior pharynx-defective 1 , and presenilin enhancer 2 [29]. Although its function is not fully understood, APP has been involved in regulation of synaptic plasticity and acts as a cell adhesion molecule that participates in several neurodevelopmental aspects such as migration, neurite outgrowth, growth cone pathfinding, and synaptogenesis $[30,31]$. Inadequate cleavage of APP may lead to formation of abnormally long peptides, such as A $\beta 1-42$ fragments, which are more likely to oligomerize and form plaques, compared with shorter fragments such as $A \beta 1-40$ [32]. Although the precise neurotoxic mechanisms of $\mathrm{A} \beta$ are not yet fully elucidated, the presence and aggregation of these peptides compromise the function of various cells including astrocytes, microglia, and neurons, leading to systemic failure of brain activity, mainly related, but not limited, to cognitive aspects $[33,34]$.

In vitro evidence indicates that $\mathrm{A} \beta$ induces the release of proinflammatory factors from astrocytes and microglia, including interleukin-1 $\beta$ (IL-1 $\beta$ ), IL-6, NO, and tumor necrosis factor alpha $(\mathrm{TNF} \alpha)[15,16]$. In addition, $\mathrm{A} \beta$ oligomers may generate free radicals and induce mitochondrial dysfunction via abnormal activation of glial cells $[35,36]$. Other pathological mechanisms include glutamate-induced neuronal excitotoxicity [37], GABAergic dysfunction [38], and reduced cerebral glucose intake [39, 40]. Ultimately, accumulation of $\mathrm{A} \beta$ peptides may trigger intracellular signaling for tau hyperphosphorylation, with formation of tau oligomers and NFT $[11,14]$ leading to neuronal degeneration [41]. Tau appears to be involved in disease progression, as tau aggregates propagate in a prion-like fashion, initiating a self-amplifying cascade and spreading to other brain regions [42]. In $\mathrm{AD}$, these aberrant proteins are deposited in several brain areas including the frontal, parietal, temporal, and occipital lobes and cause neuroinflammation, OS, metabolic dysfunction, excitotoxicity, and perturbation of synaptic plasticity [43-48].

2.2. A $\beta$ Mechanisms in the Retina. Retinal cells share a common embryonic origin with the brain and indeed are a projection of the CNS [49]. Further, they have similarities in vasculature, glial cells, neurotransmitter systems, and connectivity with the visual cortex [50]. Moreover, insoluble aggregation of $\mathrm{A} \beta$ peptides in the eye of double transgenic $\mathrm{AD}$ mice has been observed in different retinal layers, mainly 
the ganglion cell layer (GCL), nerve fiber layer (NFL), photoreceptor layer, and inner plexiform layer (IPL), leading to neuronal damage and visual symptoms [51]. Although this has not been confirmed in humans, it is hypothesized that similar changes may occur.

Glial cells play a crucial role in the biochemical and molecular mechanisms that induce neurodegeneration and are highly expressed in the mammalian retina, optic nerve, and retinal blood vessels. Astrocytes predominate in the NFL, interacting with retinal ganglion cells and in close relationship with blood vessels of the inner nuclear layer (INL) [52]. Thus, $\mathrm{A} \beta$-induced toxic effects on astrocytes and microglia may generate alterations in the eye and visual system like those found in other nervous tissues, such as the hippocampus or cortex.

Moreover, $\mathrm{A} \beta$ has been shown to produce changes in Müller cells, the main glial cells resident in the retina. An in vitro model using the immortalized human Müller cell line MIO-M1 reported that treatment with $\mathrm{A} \beta_{1-42}$ induced caspase-independent apoptosis through activation of the purinergic receptor $\mathrm{P} 2 \mathrm{X} 7$ in these cells [53]. A subretinal injection of $\mathrm{A} \beta_{1-42}$ in $\mathrm{C} 57 \mathrm{BL} / 6$ mice stimulated the development of gliosis and a proinflammatory phenotype in Müller cells, together with an increase in protein expression of cyclooxygenase 2 (COX-2), glutamine synthetase (GS), the inwardly rectifying potassium channel Kir4.1, and the aquaporin-4 (AQP-4) water channel [54]. However, studies in $\mathrm{AD}$ animal models have found contradictory results. A study using the triple transgenic mouse model, $3 \mathrm{x}$-TG-AD [55], observed strong gliotic responses and increased processes in Müller cells close to amyloid deposits, while a more recent study using the APPSWE/PS1 $\triangle \mathrm{E} 9$ mouse model failed to see any significant gliotic response or changes in GS expression [56].

Aggregation of $\mathrm{A} \beta$ plaques can lead to inflammatory reactions, reactive gliosis, and cellular and neuronal apoptosis in both the brain and retina $[43,57]$. At the very early disease stage, an increase in macular layer size is observed in amnestic MCI patients, which may correspond to inflammatory processes and/or gliosis [58]. Also, astrocytes induce the release of vascular factors such as prostaglandins, NO, and arachidonic acid, which may lead to neurovascular dysfunction in $\mathrm{AD}$ as indicated by pathological and experimental studies [59-61]. Similarly, it has been shown that levels of complement $(\mathrm{Clq})$ are elevated in close vicinity to amyloid plaques and astrocyte processes in transgenic mice [62]. In addition, C1q activation generates endothelial cell adhesion in human dermal microvascular endothelial cells [63]. Together, these mechanisms may affect retinal vessels and metabolic supply and increase metabolic injury in the GCL of the retina in the early stage of $\mathrm{AD}$ as well as during MCI (Figure 1).

Several studies in humans and animal models have identified $\mathrm{A} \beta$ plaques in the photoreceptor layer, GCL, NFL, IPL, and outer plexiform layer (OPL), which manifest at the early stage of disease, even before the appearance of neurological symptoms [64-66]. The retinal and visual effects of these plaques are not entirely clear, but activation of astrocytes and microglia, together with neuroinflammatory changes induced by $\mathrm{A} \beta$, lead to an initial increase in the retinal epithelium (RPE) and GCL degeneration in a transgenic rodent model of $\mathrm{AD}[64,67]$. In addition, an increase in the number of astrocytes and astrocyte/neuron ratio (which is associated with increased neuronal loss), especially in the superior and inferior quadrants of the retina, has been reported in humans [68]. Similar changes where neuronal numbers are reduced and nonneuronal cells are increased have been observed in human brain regions such as the hippocampus and cerebral cortex [69], as well as in the visual cortex [70]. Nonetheless, despite the previous observations of $\mathrm{A} \beta$ effects on the eye, there are limitations to mimic the clinical findings in animal models, which may point to other endogenous mechanisms present in these models and diverse adaptive changes in early phases of $\mathrm{AD}[71,72]$. Additionally, it is noteworthy to remark that $A \beta$ aggregation was also shown within the eye of individuals undergoing normal cognitive aging; however, this pathophysiological process is quite distinct from the one described in patients suffering $\mathrm{AD}$ as it is discussed below in Section 2.4.

2.3. Tau Mechanisms in the Retina. One of the hallmarks of $\mathrm{AD}$ is the presence of intraneuronal hyperphosphorylated tau protein. These tau oligomers assemble in large insoluble fibrillar structures, known as NFT, and spread between cells in both the brain and retina. Tau oligomers seem to be one of the main structures that promote inflammation in the retina at the early disease stage. Tau oligomers induce neuroinflammation in a perpetuating feed-forward cycle, propagating neural damage, augmenting tau oligomer production, and consequently triggering the appearance of more inflammation [73]. Other studies detected tau accumulation in the retina at an early phase of $\mathrm{AD}$ : before the onset of cognitive impairment and even before tau aggregation in the brain in the mouse model of $\mathrm{AD}$. In the retina, tau accumulates principally in GCL dendrites and intraretinal axons, but is depleted in optic nerve axons [74]. Some studies have demonstrated predominant accumulation of tau in GCL, but it has also been observed in the INL, IPL, OPL, and NFL $[65,75]$. Conversely, hyperphosphorylated tau has not been found in other structures such as optic nerve, cornea, and lens in $\mathrm{AD}$ transgenic mice [76, 77]. Tau accumulation causes dysfunction in anterograde axonal transport, which is a feature of neuronal impairment that occurs before the appearance of retinal cell death [74]. Tau aggregation inhibits mitochondrial transport towards the GCL periphery, leading to loss of energy production and formation of reactive oxygen species (ROS). Altogether, retinal neurons in $\mathrm{AD}$ tend to be more susceptible to $\mathrm{OS}$, produce hyperphosphorylated tau aggregates, and prolong the delay in vesicular transport that is necessary for synapse function and cellular growth [75]. Future studies comparing tau aggregation between $\mathrm{AD}$ patients, $\mathrm{MCI}$, and individuals undergoing healthy aging could be useful to clarify if tau plays any role in retinal changes in $\mathrm{AD}$ pathology.

2.4. A $\beta$, Aging, and Age-Related Macular Degeneration. During aging, the brain and retina develop extracellular deposits recognized as plaques and drusen, respectively. 


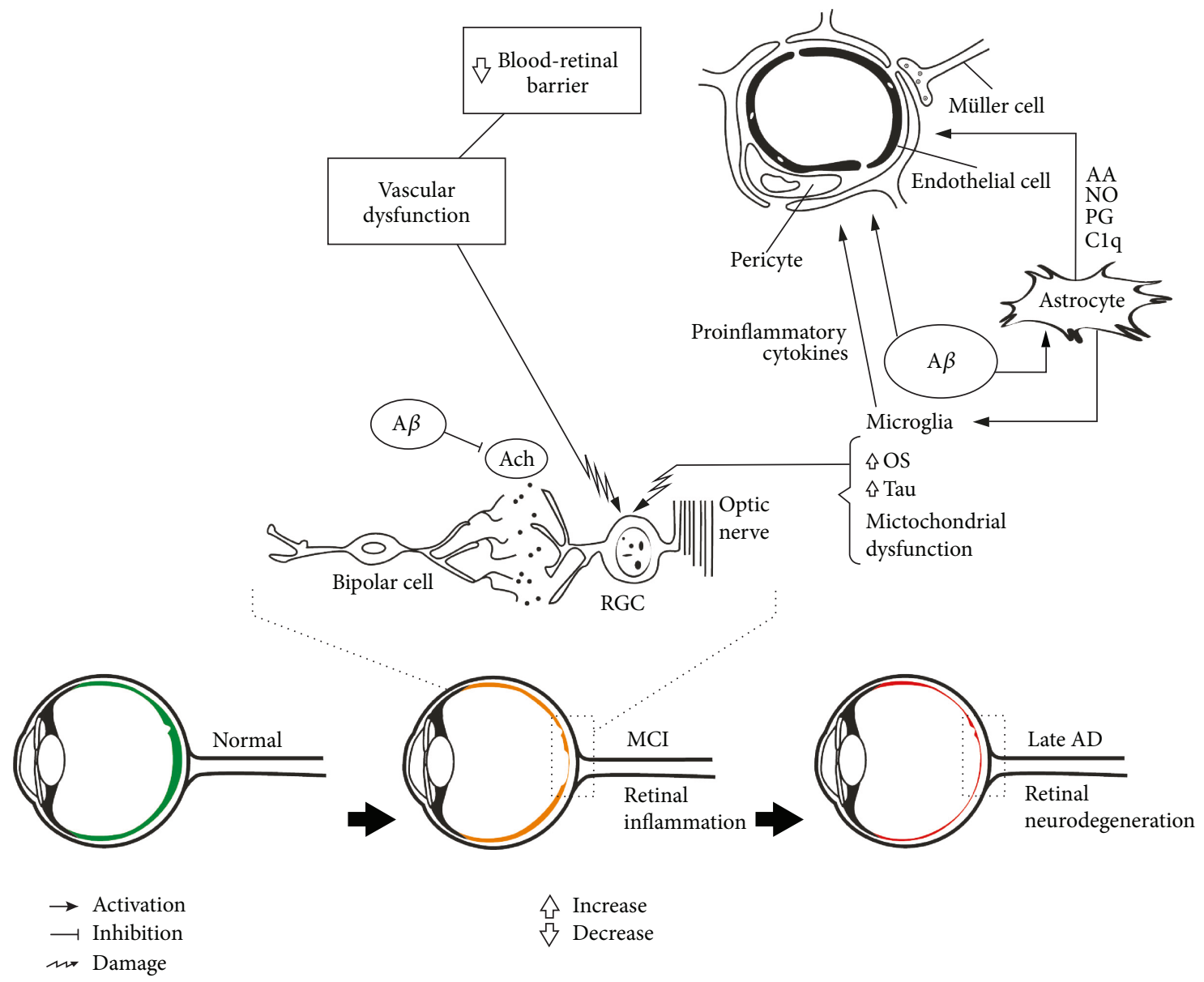

Figure 1: Pathophysiological events in the retina during Alzheimer's disease progression. Amyloid-beta (A $\beta$ ) induces microglia and astrocyte activation, synaptic dysfunction, and neurodegeneration. These interactions can be observed by noninvasive ophthalmological examinations in the retina at different stages of Alzheimer's disease (AD). Reduction in the peripapillary region and macular volume has been described in MCI and AD. AA: arachidonic acid; $\mathrm{A} \beta$ : amyloid-beta; ACh: acetylcholine; AD: Alzheimer's disease; MCI: mild cognitive impairment; NO: nitric oxide; OS: oxidative stress; PG: prostaglandins; RGC: retinal ganglion cells.

"Drusen" in the retina are deposits of insoluble cellular debris and lipids localized beneath the RPE and inner collagenous layer of Bruch's membrane (BM) [71]. Two types of "drusen" have been identified (hard and soft which differ in their location, and in their clinical and morphological appearance). Both soft and hard "drusen" have similar compositions; however, some authors suggest that each type of "drusen" may be composed by a certain variety of proteins or may be constituted by different amounts of the same components. Differences in "drusen's" morphology, composition, physical properties, and location (peripheral or central) could most likely be based on different formative mechanisms that may contribute to macular susceptibility for age-related macular degeneration (AMD) progression. Although "hard drusen" can appear everywhere in the retina, they are usually located in the peripheral retina and are characterized by hemispherical structures with well-defined borders. "Hard drusen" are considered part of the normal aging process. "Soft drusen" are located exclusively in the macula, characterized by poorly defined borders and larger size [78]. They are linked to the early stage of AMD $[72,79]$. AMD is a slow, progressive disease that compromises the macula and the primary cause of irreversible blindness during aging [43].

Two types of AMD have been described: dry AMD type, characterized by significant atrophy of RPE and the photoreceptor layer, and wet, or exudative, AMD type, with invasive blood vessels through the blood-retinal barrier [43]. These invasive vessels come from the choroid and proliferate in the retinal layers between $\mathrm{BM}$ and RPE or sometimes proliferate between RPE and the neurosensory retina. In turn, this leads to vascular leakage and fluid accumulation, with formation of fibrovascular disciform scars in the retina that can be observed by ophthalmoscopy [79].

The extracellular deposits in the brain and retina share the presence of $\mathrm{A} \beta$, ApoE, proteoglycans, immunoglobulins, metal ions, acute-phase reactants, fibrinogen, prothrombin, membrane debris, and protease elements $[43,72]$. A $\beta$ formation is found in both $\mathrm{AD}$ and $\mathrm{AMD}$, suggesting a common mechanism related to proteinopathic $\mathrm{A} \beta 1-42$ peptide deposition $[80,81]$ and imbalance between increased $A \beta$ synthesis and reduced $\mathrm{A} \beta$ removal [12]. Specifically, in the aging eye, $\mathrm{A} \beta$ accumulation occurs primarily in the outer segments of photoreceptors and at the interface between RPE and BM 
[82]. This process appears to initiate at the apical region of the outer segments and progresses through the retinal layers with age, also accumulating in choroidal blood vessels. In drusen, $A \beta$ is localized in vesicular components known as "amyloid vesicles" or "amyloid assemblies" $[43,78]$ and exhibits several shapes, diameters, and fusion processes. In addition, some drusen are described as a single large vesicle occupying a sizable portion of the drusen, or densely packed with several amyloid vesicles [43]. Amyloid vesicles are formed by amyloid oligomer cores composed of toxic oligomeric $\mathrm{A} \beta 1-42$ peptides that are centrally organized in a ring structure [82], in close proximity to the inner collagenous layer of $\mathrm{BM}[71]$. A $\beta 1-42$ interacts with different drusen components, including complement proteins ( $\mathrm{HF} 1$, $\mathrm{C} 3 \mathrm{~b} / \mathrm{iC} 3 \mathrm{~b}$, and C5), interleukins (IL-1 $\beta$, IL-8, and IL-33), and lipids (cholesterol and phosphatidylcholine) to form mature $A \beta$ fibrils, which compose the shell of amyloid vesicles $[43,82]$.

Overall, these interactions increase ROS production, which contributes to formation of glycation and lipoxidation end products [79]. Additionally, it is hypothesized that $\mathrm{A} \beta$ promotes retinal microglia translocation from the inner retina (normal position) to the subretinal space, inducing changes in RPE cells and leading to secretion of proinflammatory, chemotactic, and proangiogenic molecules [82]. Furthermore, complement proteins appear to play a key role in the pathophysiological mechanisms of $\mathrm{AD}$ owing to activation by membrane proteins, lipids, cholesterol, and $\mathrm{A} \beta$ deposits. Complement molecules promote inflammatory stimuli [72], disrupt the RPE junctional complex [82], impair trans-epithelial permeability, and induce mitochondrial damage. Moreover, they also promote an increase in angiogenic factors, such as vascular endothelial growth factor (VEGF), and decrease in anti-angiogenic factors, such as pigment epithelium-derived factor $[43,83]$.

The role of tau in AMD is debated and likely underestimated, as tau has not been found in drusen, but has been reported in OPL, INL, IPL, and NFL of patients with AD. Some studies suggest that tau aggregation in aged retina causes defective transportation of molecules, cells, and proteins, which may promote drusen formation and subsequently AMD [75].

2.5. Apolipoprotein E Mechanisms. ApoE is involved in the transport of cholesterol and triglycerides and is considered one of the most important risk factors for development of $\mathrm{AD}$ [84]. ApoE protein is mainly expressed in the brain on astrocytes, but also in microglia, neurons, pericytes, smooth muscle cells, and brain endothelial cells [85]. Of the different ApoE alleles $(\varepsilon 2, \varepsilon 3$, and $\varepsilon 4)$, ApoE4 shows a strong relationship with increased risk of developing $\mathrm{AD}$, while ApoE2 provides protection against $\mathrm{AD}$ [86]. ApoE4 interacts with $\mathrm{A} \beta$ to increase $\mathrm{A} \beta$ aggregation [87]. Furthermore, the risk of amyloidosis in $\mathrm{AD}$ is suggested to be related to the interaction between ApoE, aging, and amyloid burden [88].

ApoE4 is associated with vascular pathology in $\mathrm{AD}$ and promotes cerebral amyloid angiopathy. Further, ApoE4 is related to other vascular diseases such as atherosclerosis, stroke, cerebrovascular disease, and coronary heart disease.
Consequently, it has been proposed that the pathological effects of ApoE4 are initiated by cerebrovascular insult, which subsequently leads to neurodegeneration. In the retina of transgenic mice, ApoE4 is implicated in reduced vascular density and increased vascular buds and branching in early postnatal days, which ends during the neonatal period. These findings are associated with decreased synaptic expression after the neonatal period, due to low VEGF levels in ApoE4 models. VEGF is implicated in angiogenesis and vascular plasticity and as a neuronal growth factor in retina development. This determined that ApoE4 has transitory synaptic and vascular effects during retinal development, before and after the neonatal period, respectively. Moreover, VEGF in aged retina has proangiogenic effects that promote macular edema, diabetic retinopathy, and macular holes [89, 90].

ApoE can be expressed in RPE, GCL, and BM and is synthesized in Müller cells [89]. ApoE is involved in uptake, processing, transport, and clearance of lipids for retinal metabolism; therefore, disturbance of this process may lead to cholesterol and lipid accumulation in BM [43]. Distinct to $\mathrm{AD}, \mathrm{ApoE} 4$ confers protection against $\mathrm{AMD}$ because it improves BM permeability, facilitates lipid transportation, and consequently leads to reduced debris accumulation in drusen formation. In contrast, ApoE2 increases the risk of AMD apparition because it induces VEGF as a proangiogenic agent [43, 89, 91, 92]. Contradictorily, some studies have shown increased AMD in AD patients [93], while others show no association [94].

\section{Functional and Pathological Findings in the Visual System}

Neuronal and synaptic dysfunction in $\mathrm{AD}$ may compromise visual system pathways in associated cortical and subcortical brain structures, as well as peripheral nerves. Complex visual disruptions are described in $\mathrm{AD}$, which are related to neural dysfunction and modifications in varied eye structures. Depending on the area affected, these lead to diverse clinical manifestations, making the visual system a potential diagnostic aid [95].

3.1. Cortical, Subcortical, and Brainstem Regions. $\mathrm{A} \beta$ and NFT aggregation as well as neurodegeneration and axonal damage are found in different brain structures related to visual system functioning [50]. For instance, in the primary cortex (Brodmann areas 17 and 18) of AD patients, has been described a decrease in neuronal density, and increase in glial density only in area 17 . These cellular changes are related with the presence of $\mathrm{A} \beta$-plaques and NFT [70]. In the case of the secondary visual cortex, involvement of the cuneal and lingual areas of the occipital lobe of $\mathrm{AD}$ cases may correspond with impairment in selective visual attention, emotion, and visual processing [96-98]. Meanwhile, reduced glucose metabolism in the visual association cortex and inferior parietal cortex might be related to abnormalities in figure copying, color vision tested by isochromatic plates, and stereopsis [99].

Regarding subcortical structures, $A \beta$ aggregation and neuritic plaques have been found in the pulvinar nucleus of 
the thalamus of $\mathrm{AD}$ postmortem samples. This nucleus participates in visual attention and in the control of eye movements [100]. Similarly, amyloid pathology in the lateral geniculate nucleus of the thalamus, the initial processor of visual information, has been reported. In this regard, a reduction in the number of parvocellular neurons and magnocellular gliosis was found [101]. Indeed, the magnocellular system is involved in recognition of movement, spatial perception, and luminosity, meanwhile parvocellular on identification of color and form. Correspondingly, color and motion perception is affected in $\mathrm{AD}$ patients [21]. Another structure involved would be the suprachiasmatic nucleus, responsible of the circadian cycle, sleep, melatonin secretion, pupil regulation, and learning. In fact, clinical and animal models of $\mathrm{AD}$ indicate severe disturbance in the circadian rhythms, as well as neurodegeneration in brain structures which control those cycles [102-105]. Altogether, cortical and subcortical dysfunction of the visual system may partially explain the difficulties $\mathrm{AD}$ patients have with writing, reading, color and structure differentiation, facial recognition, and visual acuity.

Amyloid aggregation, NFT, and neuritic plaques in the superior colliculus, responsible for the onset of ocular movements, have been reported in postmortem samples from the brainstem of $\mathrm{AD}$ patients $[106,107]$. Accumulation of $\mathrm{A} \beta$ has also been observed in the EdingerWestphal nucleus of the parasympathetic oculomotor system (which is responsible for pupillary constriction), resulting in degeneration, neuronal loss, and decreased acetylcholine (ACh) in this nucleus, with consequent pupillary reflex alterations $[22,46]$. The sympathetic system, involved in the dilatation of the pupil, is also affected in more advanced $\mathrm{AD}$ stages [46].

$\mathrm{ACh}$ is well known as an excitatory neurotransmitter in the learning and memory process [108] and is compromised in $\mathrm{AD}$. Indeed, changes in neurotransmitter function may explain retinal and visual dysfunction in early $\mathrm{AD}$ and $\mathrm{MCI}$ before neurodegeneration is established. Different studies have shown neurotransmitter synthesis in amacrine cells, and nicotinic receptors in bipolar cells, horizontal cells, photoreceptors, and the GCL $[108,109]$. In the retina of a transgenic mouse model of $\mathrm{AD}(\mathrm{Tg}-\mathrm{SwDI})$, specific cholinergic cell loss together with reactive gliosis was found [108]. Cholinergic dysfunction induced by $\mathrm{A} \beta$ is established at distinct levels: neurodegeneration of cholinergic cells [110], ACh depletion [111], impaired ACh release [112], and finally $\mathrm{A} \beta$-induced impairment of muscarinic [113] and nicotinic acetylcholine receptors (e.g., $\alpha 7$-nAChR) [114], as well as associated effectors (e.g., potassium voltage-gated channels, KCNQ) [115-117]. In older animal models, downregulation of $\alpha 4, \alpha 7, \alpha 9$, and $\alpha 10 \mathrm{nAChR}$, and $\mathrm{m} 4$ and $\mathrm{m} 5$ muscarinic acetylcholine receptor (mAChR) subunits, was found. These changes are observed in photoreceptors and INL cells, accompanied by cholinergic cell loss in the retina [108]. Contrast sensitivity and visual attention has been found to be deteriorated in $\mathrm{AD}$ patients [118]. In this regard, the use of cholinergic drugs such as donepezil leads to improvement in visual selective attention [119]. Similarly, donepezil also increases contrast sensitivity and accuracy in non-AD subjects [120]. Therefore, the stimulation of the cholinergic system in $\mathrm{AD}$ patients not only may generate improvement in learning and memory processes but also might improve visual alteration at retinal, subcortical, and cortical levels.

3.2. Retina. In the retina, GCL, NFL, IPL, and the photoreceptor layer can generate $\mathrm{A} \beta$, as each layer expresses APP [30]. As described earlier, aberrant APP cleavage leads to neurotoxic $A \beta$ aggregation, enabling inflammatory processing, degeneration, and thinning in all quadrants of the retina in these layers, but mainly in the superior and inferior quadrants. These layers are present in a third of the macula; therefore, any alterations can contribute to reduced macula and fovea volume, which may partially explain the ocular manifestations that these patients exhibit [25, 48, 121-124]. Study in retinas from postmortem patients with $\mathrm{AD}$ found a reduction in the number of GCL neurons related to progressive aging [125]. In contrast, GCL thinning was aggravated in patients with $\mathrm{AD}$ and not related to aging in other studies [126]. AD ocular findings in human studies are summarized in Table 1, and findings in animal studies are summarized in Table 2.

3.3. Optic Nerve. Analysis of the optic disc has been performed in $\mathrm{AD}$ patients, with increased cup-to-disc ratio [50], higher pallor area-to-disc area ratio, and decreased disc rim area of the optic nerve observed as indirect signs of axonal damage $[21,127,128]$. These optic nerve alterations are due to degeneration of axons and larger cells of the GCL and NFL [127] in the central and peripheral portions of the retina, which are involved in the magnocellular pathway and ensure greater optic nerve caliber [129]. In addition, reduced hemoglobin percentage in the neuroretinal rim and increased cup-to disc ratio (by 39\%-43\%) have been demonstrated $[128,130,131]$. Nonetheless, despite significant reduction of the density of axons from the optic nerve in $\mathrm{AD}$ when compared with the age-matched control subjects, no correlation between optic nerve volume and cerebral volume in $\mathrm{AD}$ patients was observed [132].

3.4. Retinal Vasculature. Regarding the vasculature, $\mathrm{A} \beta$ protein can be found in the walls of retinal blood vessels. Its integrity is important in maintaining the blood-brain barrier [44]. However, with aging, $\mathrm{A} \beta$ protein aggregates and accumulates in blood vessels of the cerebral and retinal vasculature [126]. As already described, retinal microvasculature has the same embryological origin as brain microvasculature, sharing disease-specific pathological mechanisms [44]. Different clinical studies have shown venular narrowing [133] with a decrease in flow, vessel diameter [134, 135], arteriolar-venular fractal dimension [133], and branching pattern [136] in AD. Similarly, increased arterial tortuosity has been observed in clinical studies [133], with standard deviation of vessel width [136] and amplitude of arterial pulsation [126, 133, 136, 137]. Moreover, these findings relate to cognitive impairment, disease progression, and reduction in NFL diameter in the superior quadrant $[21,26,27,138-140]$. Although other studies differ in these conclusions, no significant variations were shown for 


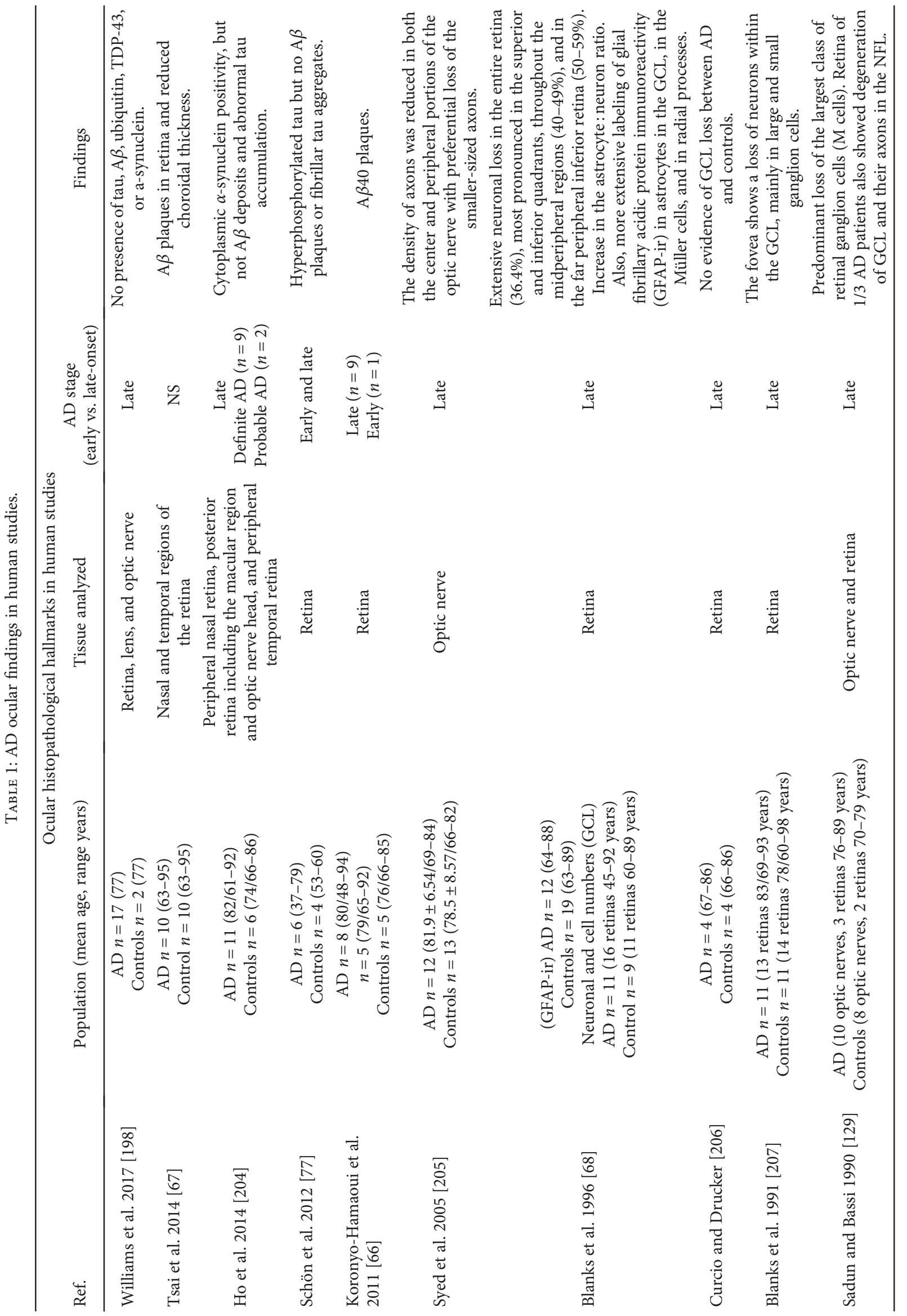




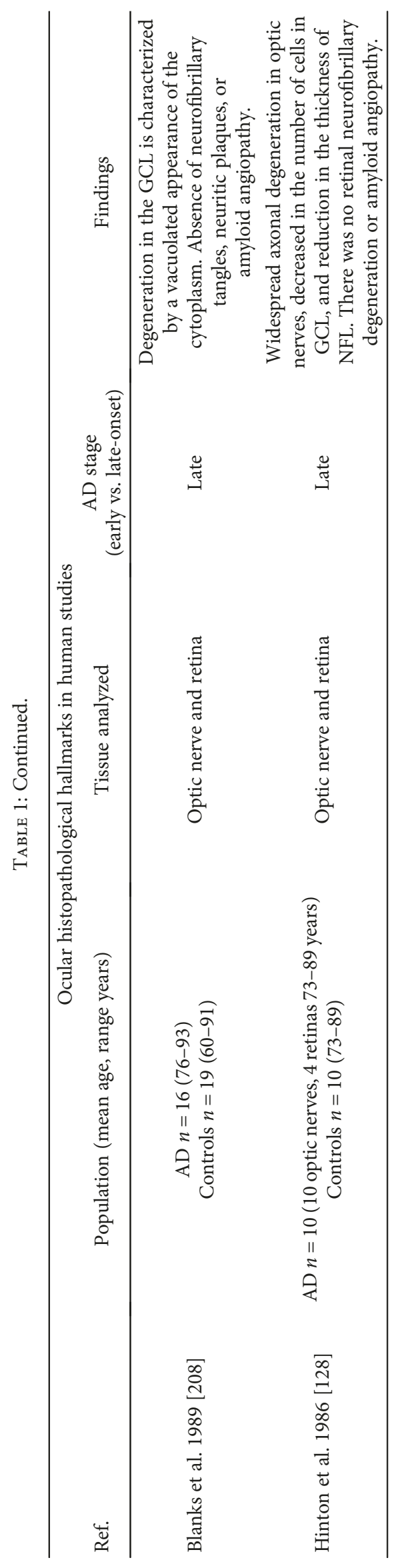




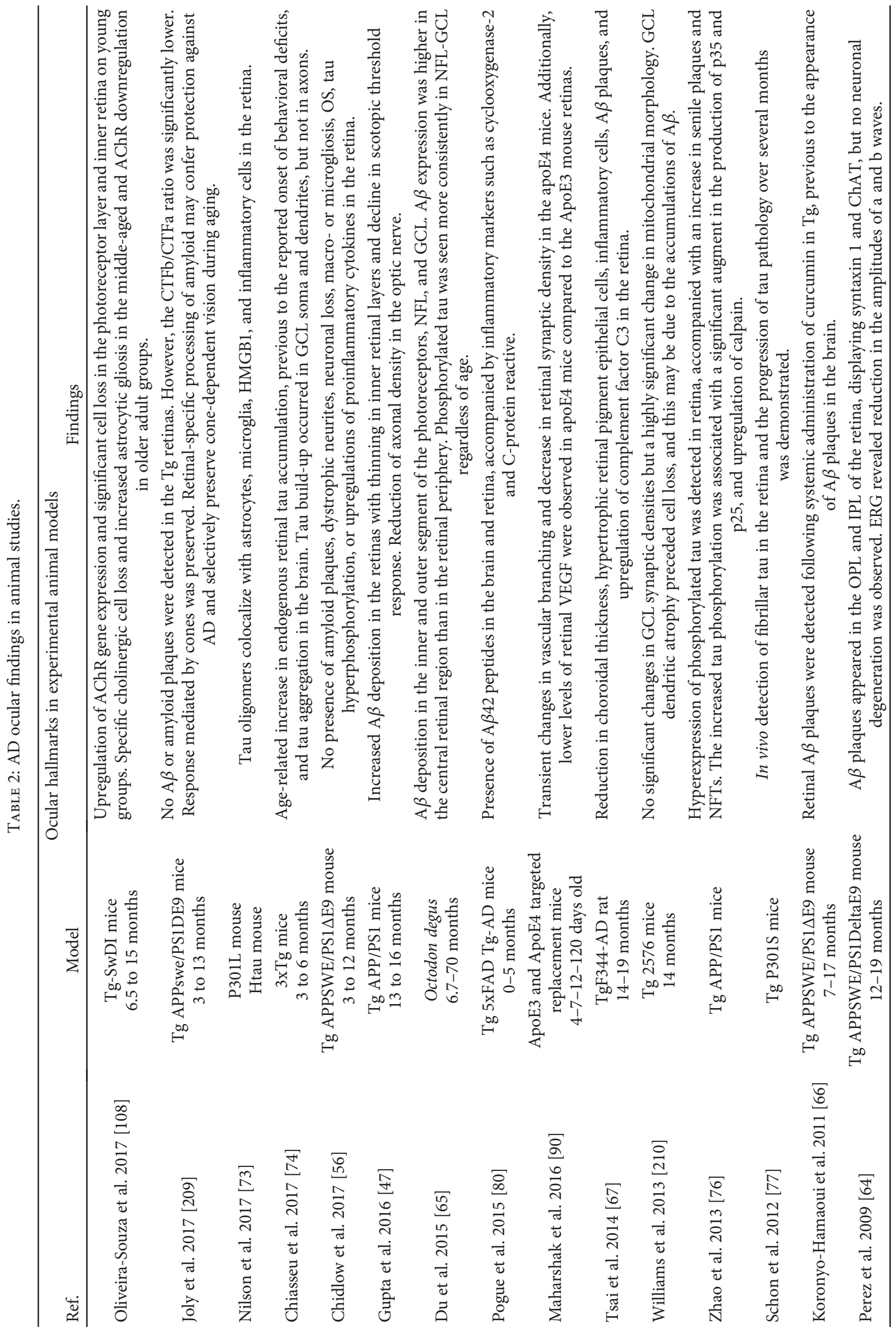


arteriolar-venular caliber, branching angle, or venular tortuosity in $\mathrm{AD}$ patients [133].

\section{Visual Impairments in AD: Clinical Features}

$\mathrm{AD}$ affects different structures of the visual system in a similar pathological manner as the brain, with manifestation of distinct signs and symptoms that can be determined by adequate clinical history and ophthalmological examination. To our knowledge, there are no studies showing the chronological clinical manifestations specifically correlated with changes in the retina in patients with AD. Therefore, it is important to conduct clinical prospective studies in order to clarify this aspect. Regarding structural changes in the retina, thinning of the superior or inferior quadrants has been described in $\mathrm{AD}$ patients associated with visual field impairment. Other visual findings have been correlated with alterations in the brain [141]. Regarding early visual manifestations, it has been observed that contrast sensitivity is the first visual dysfunction found in animal models and $\mathrm{AD}$ patients $[142,143]$. The rest of visual symptoms are evident depending on the compromised brain structure [22, 95, 144].

Complex visual disturbances are described in patients with $\mathrm{AD}$, including constructional and visuoperceptual disorientation, specifically difficulties in searching for objects (figure-ground discrimination), finding their way in familiar surroundings (environmental agnosia) [99, 145], and spatial recognition or spatial order memory (spatial agnosia) [146]. Additionally, distinct alterations in daily life activities due to deterioration in visual attention [147] and impairments in tasks requiring semantic access from visual information (e.g., disproportionate reading [148] and facial recognition [149]) are observed. With facial recognition, transient misidentification, abnormal self-identification, Capgras syndrome (denial of a familiar person and identifying them as a replacement, imposter, or double), and in some cases prosopagnosia (disordered recognition of familiar faces) have been described [150]. These disturbances are due to disordered visual processing because of disrupted corticocortical projections as a result of alterations in cortical and visual pathways (i.e., occipito-parietal and occipitotemporal) $[151,152]$. Disordered visual processing can lead to complications in perceiving and comparing visual stimuli, alterations in processing visual stimuli, and impairments in long-term memory and generating verbal or action responses [148].

Another visual disturbance identified in AD is Balint's syndrome. This is an uncommon and incompletely understood visuospatial defect reported in patients with bilateral parieto-occipital damage associated with Brodmann's area $7 \mathrm{~b}$ in the posterior parietal lobe (which is involved in control of pursuit ocular movements and target gaze on a stimulus) and superior occipital cortex areas 17, 18, and 19 (which are involved in visual field construction) [153]. Balint's syndrome is characterized by simultanagnosia (difficulties in locating, reaching, or attending to multiple items in a visual space), ocular motor apraxia (inability to maintain fixation on a specific point located in the peripheral visual field), and optic ataxia (inappropriate coordination of voluntary movements in response to a visual stimulus) [149].

Recently, alterations in ophthalmologic examination of $\mathrm{AD}$ patients have been described. These alterations include decreased visual acuity, with difficulties in writing and reading [154] increasing along with disease progression $[139,155,156]$. Similarly, compromised contrast sensitivity (ability to distinguish an object on a background of different frequencies) $[142-144,157]$ has been observed as a principal manifestation during the initial disease stage, with progressive impairment throughout the disease course [143]. Contrast sensitivity is associated with damage to the magnocellular pathway in the geniculate nucleus of the CNS, which is involved in the ability to identify luminosity and motion perception [158]. Another manifestation in AD patients is fluctuations in color perception, mainly errors in color recognition, due to involvement of the parvocellular pathway, which is characterized by smaller axons of the optic nerve [159]. Additionally, pupillary reflex deficits are reported as a deficiency of the sympathetic and parasympathetic systems, with the principal findings being decreased amplitude, speed, and latency of reflexes. Further, smaller resting pupil diameter and maximum dilatation velocity in the dark [160] as well as reduced amplitude and $75 \%$ recovery time of the light reflex response $[22,160]$ are also reported. Other abnormalities in ocular movement, decreased movement perception, and stereopsis dysfunction have been observed in patients with $\mathrm{AD}$ [46]. These abnormalities include inability to focus on an object (less relative fixation time) [161], irregular convergence angle, difficulty performing saccadic ocular movements $[162,163]$, poorer heading and speed perception at lower temporal periodicity [24], and inability to identify three-dimensional objects [164]. Finally, loss of the visual field mainly occurs in the inferior quadrant and is related to GCL damage in the superior quadrant of the corresponding retina [96]. Visual field loss is characterized by accumulation of larger SP and greater amounts of NFT in the cuneal gyrus than lingual gyrus of the visual cortex, which is where nerve fiber projections of the GCL in the superior and inferior quadrants terminate, respectively [135].

\section{Paraclinical Visual Studies in AD}

Different noninvasive imaging methods have been developed to study structures of the visual system and visual pathways in $\mathrm{AD}$ patients. In this section, we describe findings obtained by optical coherence tomography (OCT) and bioelectrical changes through electrophysiological examinations, specifically electroretinograms (ERG) and visual evoked potentials (VEP).

5.1. Optical Coherence Tomography in the Retina. In the retina, different OCT methods based on cross-sectional images of the retinal layers have been performed in $\mathrm{AD}$ patients, including spectral domain-optical coherence tomography (SD-OCT). Using SD-OCT, thinning and thickening of NFL in the superior and inferior quadrants, respectively, of the nasal and temporal regions were related [165] to cognitive impairment $[131,166,167]$. Degeneration of NFL, 
GCL, and IPL has been related to AD duration, with longer disease duration associated with greater damage to the retinal layers. The most affected quadrants were the temporal, temporal-inferior, and temporal-superior sectors, with increased nasal/temporal ratio reflecting higher temporal sector commitment. In addition, reduction of the GCL was associated with axonal degeneration, which may predict greater disease severity [168].

Among other OCT studies, progressive compromise of the NFL was shown between an intermediate group with MCI and different disease stages. Thinning of NFL in the superior quadrant was gradually affected among patients with MCI and mild AD. The inferior quadrant was involved in severe disease stages, demonstrating engagement of the NFL throughout disease progression [169]. In addition, another study detected a decrease in NFL in AD and MCI groups in the inferior quadrant, with the superior quadrant significantly compromised in AD patients only [170]. Contrarily, NFL thinning was evident in all $\mathrm{MCI}$ and $\mathrm{AD}$ groups, indicating that NFL involvement is observed in the early disease stage [171]. Furthermore, significant NFL thinning was identified in patients at the early stage of $\mathrm{AD}$ [165]. A meta-analysis of 51 articles in the last 5 years recognized that loss of NFL mainly occurred in the superior quadrant, yet corresponded to visual field impairments in the inferior quadrant. This deterioration in NFL was related to disease duration in $\mathrm{AD}$ [140].

When comparing $\mathrm{AD}$ patients and healthy controls, a significant NFL reduction has been observed in $\mathrm{AD}$ patients, more prominent in the inferior $[172,173]$ and superior quadrants $[140,174]$. A meta-analysis including $887 \mathrm{AD}$ patients and 864 controls evidenced peripapillary NFL thinning in the superior and inferior quadrants of the retina in $\mathrm{AD}$ patients that was not present in controls [175]. Additionally, AD patients had reduced thickness in GCL, NFL, IPL, and outer nuclear layer (ONL) compared with controls [176].

In contrast, a relationship between NFL involvement (through OCT) and cognitive impairment by Mini-Mental State Examination (MMSE) was reported in AD patients, suggesting that measurement of NFL may be used as a disease progression marker [177]. However, other studies have observed NFL thinning in all quadrants, especially the nasal region, with no relationship to the MMSE and $\mathrm{AD}$ severity [178].

5.2. Optical Coherence Tomography in the Macula. The macula is the principal structure affected at the early stage in $\mathrm{AD}$ patients. By $\mathrm{OCT}$, decreased macula volume was observed in the four internal quadrants and one temporal external quadrant, with no significant difference in decrease in peripapillary region volume in $\mathrm{AD}$ patients [179]. However, a recent meta-analysis has shown that $\mathrm{AD}$ and $\mathrm{MCI}$ patients had lower peripapillary retinal NFL compared with controls [180]. Using SD-OCT, increased macular size and IPL was shown in patients with MCI and those at risk of developing $\mathrm{AD}$, suggesting an inflammatory process and reactive gliosis in the early disease stage before establishment of $\mathrm{AD}[172,174]$. Conversely, macular thinning was identified in MCI [178] and in all sectors except the fovea, mainly in NFL of the superior quadrant in AD [156]. Decreased IPL in the inferonasal, inferotemporal, and superotemporal sectors was observed, as well as reduced NFL in the temporal sector in patients with MCI who developed $\mathrm{AD}$ two years later. Corroboratively, these results were related to cognitive impairment [176]. Macular atrophy has been described as the first manifestation in patients with $\mathrm{AD}$ and is related to degree of cognitive impairment in the MMSE [140]. By frequency domain optical coherence tomography in $\mathrm{AD}$, NFL, GCL, and IPL are shown to be reduced in size in the macula, except in the inferior external quadrant. Again, this thinning is related to MMSE results [181].

5.3. Optical Coherence Tomography in the Choroid. Choroid reduction and thinning are observed in $\mathrm{AD}$. Using SDOCT, thinning of the choroid was measured in the macula at 13 locations (separated by $500 \mathrm{~mm}$ ) in elderly compared with healthy subjects. A significant decrease in the choroid was shown in all 13 locations, but principally in two locations temporal to the fovea. This indicates that compromise in the choroid is not related to age [182]. By OCT examination over a period of 12 months, greater choroid reduction was characterized in $\mathrm{AD}$ patients compared with controls of the same age [183]. Another study measured thickness of GCL in the macula, the choroid, and external retina, and compared them with MMSE results. GCL thinning in the superior and inferior quadrants of the macula was observed, with significant thinning of the choroid in all regions. Further, a relationship was observed between GCL thinning in the macula and MMSE results, but not with choroid thinning, which was unrelated to severity of cognitive damage [173].

5.4. Electrophysiological Examination. Electrophysiological examinations (i.e., bioelectrical changes in the visual system) such as VEP and ERG have been performed in patients with $\mathrm{AD}$ [140]. VEP extracts signals directly from the visual cortex, which are dependent on adequate integrity of the visual system (eye, retina, optic nerve, and visual cortex). In patients with $\mathrm{AD}$, decreased amplitude of $\mathrm{P} 2$ or $\mathrm{P} 100$ components are observed at $100 \mathrm{~ms}[45,46,48,96,138-140,175$, 184-186]. Yet, other studies have shown no changes in pattern-VEP nor association with NFL thinning [187] in the peripapillary or macular regions [188].

The pattern ERG (PERG) test presents three peaks: negative-positive-negative, which are observed at $35-50-95 \mathrm{~ms}$, respectively [46]. Most studies show decreased amplitudes and time delays, mainly in N35, P50, and N95 components, in PERG of patients with AD $[140,189]$. In contrast, only reduced P50-N95 amplitudes with increased implicit P50 time [190] were shown in other studies, while a compromised magnocellular pathway was also reported [158]. All these findings relate to damage at the GCL level (N95) [190]. Conversely, further studies detected no PERG changes [191]. In another type of exam, the multifocal ERG, which evaluates macula functionality, even in early or intermediate states of the disease in patients with $\mathrm{AD}$, a statistically significant reduction in the electric activity of the macula has been registered, especially in the foveal and parafoveal regions, due to the decrease in the amplitude of the P1 component 
[145]. In PERG, reduced mean amplitudes in these components were observed in patients with $\mathrm{AD}$. This anomaly may be due to axonal depletion within the optic nerve as well as GCL degeneration [192]. Additionally, PERG at different frequencies showed amplitude reductions at high frequencies in patients with $\mathrm{AD}$ [193]. In other types of examination, namely, pattern-reversal VEP and ERG, no alterations were detected, but delays were occasionally demonstrated in the second positive component of flash VEP [192]. Scotopic and photopic flash ERG and oscillatory potentials show no alterations between both methods in patients with $\mathrm{AD}$, suggesting no visual pathway involvement [194]. With VEP, decreased latency in the magnocellular pathway was observed in AD patients [158].

\section{Future Clinical Directions}

The clinical study of the visual system offers several benefits owing to the relatively scarce invasiveness of the examination, as well as the associated low cost of procedures. Structural eye components such as the cornea, lens, retina, and optic nerve can be observed with an ophthalmoscope. Additionally, functional aspects related to autonomic features, such as pupillary reflex, can be directly studied. Further, a wide array of visual paraclinical tests have been developed including VEP, ERG, tonometry, and OCT. These procedures are not limited to evaluating aspects of the visual system and can also be used to examine neurological or systemic components of many conditions. This has led to the proposition that studying the visual system is a helpful and complementary approach with biomarker potential in neurodegenerative conditions, including $\mathrm{AD}$ [45]. Many visual changes manifest in $\mathrm{AD}$ patients (as already discussed), including alterations in visual acuity, color perception, contrast sensitivity, the visual field, pupillary reflexes, ocular movements, and stereopsis. All can be examined by simple, noninvasive, and easily accessible methods such as adequate ophthalmologic examination, OCT, and electrophysiological examinations. These are supporting diagnostic tools that could potentially even be used in the early disease stage. Current biomarkers for $\mathrm{AD}$ tend to be either expensive or invasive, and in particular for countries with poor and inadequate healthcare systems. Moreover, no current biomarkers predict with absolute confidence, conversion of $\mathrm{MCI}$ to $\mathrm{AD}$, or development of sporadic $\mathrm{AD}$. For a recent review on the advantages and disadvantages of current $\mathrm{AD}$ biomarkers, refer to [20]. Several findings in the visual system point to the useful role of eye examinations for determination of $\mathrm{AD}$. One of the challenges of this approach is to differentiate changes related to normal aging from those of pathological origin. To date, three structural components of the eye, the retina, eye vasculature, and lens, have emerged as interesting research areas in $\mathrm{AD}$ [45].

Study of the retina and associated structures has shown $\mathrm{AD}$-related changes in preclinical (phase 1) animal exploratory models, thereby providing hints for their utility as biomarkers in humans. Many of these studies have been performed in transgenic humanized rodent models expressing $\mathrm{AD}$ characteristics. Accumulation of $\mathrm{A} \beta$ in plaques was observed at 12 months in the retina of transgenic APPswe/ $\mathrm{PS} 1 \triangle \mathrm{E} 9$ mice. These plaques localized mainly in the OPL and IPL and increased in number and size with age [64]. Similar results were also observed in transgenic APPswe/PS1 $\triangle \mathrm{E} 9$ rats, with $\mathrm{A} \beta$ plaque-like structures present in the retina, together with choroidal thinning [67]. A $\beta$ peptides were observed in the inner and outer segments of photoreceptors, NFL, and GCL, with higher expression in the central retinal region, in the Chilean rodent, Octodon degus [65], which has been suggested as a possible natural model of AD [195]. Some studies in transgenic mice have even reported earlier appearance of plaques in the retina than brain [42]. Furthermore, changes in retinal plaques can be individually monitored in real time following glatiramer acetate immunization in mice [66]. Regrettably, these results using similar animal models have not always been consistent, with contradictory findings reported. In a recently published study on APPswe/PS1 $\triangle \mathrm{E} 9$ mice, researchers were unable to demonstrate the presence of amyloid plaques, dystrophic neurites, neuronal loss, macro- or microgliosis, aberrant cell cycle re-entry, OS, tau hyperphosphorylation, or upregulation of proinflammatory cytokines or stress signaling molecules in the retina [56]. Despite promising results obtained in preclinical models, more investigations are needed to address the reasons why $\mathrm{AD}$-related changes are not constant in all animal models and explore the mechanisms inducing cellular and molecular alterations in the retina. Comprehension of these questions is vital if visual components are to be translated from basic science to clinical practice as reliable biomarkers.

Changes in the human retina have also been reported in relation to $\mathrm{AD}$. A recent meta-analysis, which included 25 studies comprising $887 \mathrm{AD}$ patients, $216 \mathrm{MCI}$ patients, and 864 healthy controls, concluded that $\mathrm{AD}$ and MCI patients show decreased retinal thickness measured by OCT [180]. Another meta-analysis, which included a lower number of studies and patients, reached a similar conclusion, corroborating the role of OCT and retinal measurement in assessment of $\mathrm{AD}[123,196]$. Accordingly, retinal measurements in humans may help distinguish between different neurodegenerative conditions. Patients with frontotemporal degeneration have a thinner outer retina, including a thinner ONL. In contrast, $\mathrm{AD}$ patients tend to exhibit inner retinal thinning [197]. Despite these encouraging results, in a similar fashion to the animal models, some reports challenge this evidence. In a recent paper, Tau, $\mathrm{A} \beta$, transactive response DNAbinding protein 43 , ubiquitin, and $\alpha$-synuclein were examined by immunohistochemistry in postmortem $\mathrm{AD}$ patient brains, showing no evidence of inclusions, deposits, or accumulation of other proteins in any part of the ocular globe [198]. As in preclinical experiments, human studies need to be expanded to clarify these controversial aspects of $\mathrm{AD}$-induced changes in the retina and visual system.

Other aspects of the eye and visual system are also reported to show alterations related to $\mathrm{AD}$, although the retina is the component that has been most thoroughly studied. In the lens, some but not all clinical studies show A $\beta$ deposition [199], while others have concluded that cataract grade or lens opacity is unlikely to provide a noninvasive 
measure of the risk of developing AD dementia [200]. These controversial results do not support the use of lens examination as a biomarker of $\mathrm{AD}$, underscoring the importance of conducting more detailed, controlled clinical studies with a larger number of patients. Ocular vascular changes have also been reported in $\mathrm{AD}$ patients [26, 201], which suggest similar microvascular damage in the eye as the well-described cerebral amyloid angiopathy owing to vascular $\mathrm{A} \beta$ deposition [202]. Direct and minimally invasive observation of eye vasculature, mainly retinal, provides an advantage to using vascular changes as a marker of AD. Unfortunately, the current evidence is not strong enough to offer a definitive answer on using this approach as a biomarker for $\mathrm{AD}$. A recent systematic review, which included all published studies applying fundus camera imaging to examine association between retinal vasculature/retinopathy and any form of dementia, found many inconsistent results regarding changes in vessel caliber, tortuosity, and fractal dimension, although the authors concluded that retinopathy was more prevalent in dementia [203]. One possible explanation for the variation in results was suggested to be the absence of histopathological confirmation of $\mathrm{AD}$ diagnosis as well as lack of dementia severity reports. However, some studies using immunohistochemistry have reported absence of markers for $\mathrm{AD}$ in the visual system (Tables 1 and 2). A recent investigation done on postmortem eye tissue obtained from $\mathrm{AD}$ patients failed to report any indication of tau, A $\beta$, TDP-43, ubiquitin, or $\alpha$-synuclein and showed no evidence of inclusions, deposits, or other protein accumulation in any region of the globe [198]. A similar result was obtained in another postmortem study, where no $\mathrm{A} \beta$ deposits or abnormal tau accumulations were detected in the lens, retina, or other structures in the eyes of AD patients [204]. Another study found hyperphosphorylated tau but not $\mathrm{A} \beta$ aggregates in postmortem retinas from $\mathrm{AD}$ patients [77]. These results contrast previously mentioned studies where $\mathrm{AD}$ pathological changes in the eyes were found. Differences in experimental procedures or in $\mathrm{AD}$ disease stage may partly explain some of these discrepancies. Nonetheless, the reported absence of AD markers in the eye may suggest that the disease compromises or develops in a dissimilar manner in the brain and in the eye. As well, other biochemical, structural, or imaging markers (i.e., OCT) in the visual system may be more adequate than $\mathrm{A} \beta$ or tau in the eye. This points to the need for developing future studies with more precise inclusion/exclusion criteria, larger patient populations with clear $\mathrm{AD}$ severity classifications and staging (for example, MCI, EOAD, and LOAD), and standardized measurements for vasculature analysis.

Currently, several clinical trials are being conducted to help clarify the use of visual components as possible biomarkers for AD. The National Institutes of Health- (NIH-) supported webpage that is responsible for the registry of clinical trials (https://clinicaltrials.gov/) has 38 studies related to $\mathrm{AD}$ and the eye. These studies have a wide range of objectives including measurement of saccades and eye-tracking, visuospatial attention, retinal thickness, and amyloid deposition. Although studying optic changes in $\mathrm{AD}$ is not without controversy, it represents a promising target that needs to be carefully studied in the future, both in preclinical and clinical studies, as the potential benefit of eye examinations as biomarkers for $\mathrm{AD}$, in particular for detection of early changes, could have a significant impact in clinical practice.

\section{Conclusions}

The visual system might rise to be an important biomarker of $\mathrm{AD}$ because the functional and pathological mechanisms with the CNS are similar. AD patients manifest a reduction in thickness of the retina, explained by a selective neurodegenerative process induced by $\mathrm{A} \beta$. Although the precise reason why certain retinal layers or quadrants are affected is not clear, neuronal loss is the result of the presence of several mechanisms such as inflammation, oxidative stress, and vascular dysfunction. There are divergent points of view about the relationship between ocular manifestations that need to be clarified. However, a better knowledge of pathophysiological mechanisms could lead to the development of new biomarkers during early stages of the disease. Ocular and visual examinations in $\mathrm{AD}$ would be a less invasive and more cost-effective method, than the techniques that are currently used. Noninvasive ophthalmological assessment could complement the $\mathrm{AD}$ diagnosis and would be a helpful tool to evaluate the disease progression. Novel functional studies of the visual system, as well as objective measurements of vascular and inflammatory changes in the eye, may play an important role in the evaluation of early stages of $\mathrm{AD}$, including $\mathrm{MCI}$ and people at risk of dementia.

\section{Abbreviations}

ACh: Acetylcholine

AD: $\quad$ Alzheimer's disease

A $\beta$ : $\quad$ Amyloid-beta

AMD: Age-related macular degeneration

ApoE: Apolipoprotein E

APP: Amyloid precursor protein

BACE-1: Beta-site amyloid precursor protein cleaving enzyme 1

BM: $\quad$ Bruch's membrane

CNS: Central nervous system

EOAD: Early-onset Alzheimer's disease

ERG: Electroretinogram

GCL: $\quad$ Ganglion cell layer

IL-1 $\beta$ : Interleukin- $1 \beta$

IL-6: $\quad$ Interleukin-6

IL-8: $\quad$ Interleukin-8

IL-33: Interleukin-33

INL: Inner nuclear layer

IPL: Inner plexiform layer

LOAD: Late-onset AD

mAChR: Muscarinic acetylcholine receptor

MCI: Mild cognitive impairment

MMSE: Mini-Mental State Examination

nAChR: Nicotinic acetylcholine receptor

NIH: National Institutes of Health

NFL: Nerve fiber layer

NFT: $\quad$ Neurofibrillary tangles

NO: $\quad$ Nitric oxide 
OCT: Optical coherence tomography

ONL: $\quad$ Outer nuclear layer

OPL: $\quad$ Outer plexiform layer

OS: $\quad$ Oxidative stress

ROS: $\quad$ Reactive oxygen species

RPE: Retinal pigment epithelium

SD-OCT: Spectral domain-optical coherence tomography

SP: $\quad$ Senile plaques

VEP: $\quad$ Visual evoked potential.

\section{Conflicts of Interest}

The authors declare no conflicts of interest.

\section{Authors' Contributions}

María Alejandra Cerquera-Jaramillo and Mauricio O. NavaMesa have contributed equally to this paper.

\section{Acknowledgments}

We thank Rachel James, Ph.D., from Edanz Group (http://www.edanzediting.com/ac) for editing a draft of this manuscript.

\section{References}

[1] P. Scheltens, K. Blennow, M. M. B. Breteler et al., "Alzheimer's disease," The Lancet, vol. 388, no. 10043, pp. 505-517, 2016.

[2] G. M. Ashraf, S. Chibber, Mohammad et al., "Recent updates on the association between Alzheimer's disease and vascular dementia," Medicinal Chemistry, vol. 12, no. 3, pp. 226237, 2016.

[3] M. Prince, A. Wimo, M. Guerchet, G.-C. Ali, Y.-T. Wu, and M. Prina, World Alzheimer Report 2015: The Global Impact of Dementia: an Analysis of Prevalence, Incidence, Cost and Trends, Alzheimer's Disease International, London, 2015.

[4] R. A. Hickman, A. Faustin, and T. Wisniewski, "Alzheimer disease and its growing epidemic: risk factors, biomarkers, and the urgent need for therapeutics," Neurologic Clinics, vol. 34, no. 4, pp. 941-953, 2016.

[5] C. A. Lane, J. Hardy, and J. M. Schott, "Alzheimer's disease," European Journal of Neurology, vol. 25, no. 1, pp. 59-70, 2018.

[6] C. R. Jack Jr, M. S. Albert, D. S. Knopman et al., "Introduction to the recommendations from the National Institute on Aging-Alzheimer's Association workgroups on diagnostic guidelines for Alzheimer's disease," Alzheimer's \& Dementia: The Journal of the Alzheimer's Association, vol. 7, no. 3, pp. 257-262, 2011.

[7] M. F. Mendez, "Early-onset Alzheimer disease," Neurologic Clinics, vol. 35, no. 2, pp. 263-281, 2017.

[8] A. L. Pierce, S. S. Bullain, and C. H. Kawas, "Late-onset Alzheimer disease," Neurologic Clinics, vol. 35, no. 2, pp. 283-293, 2017.

[9] I. Bos, S. J. Vos, L. Frölich et al., "The frequency and influence of dementia risk factors in prodromal Alzheimer's disease," Neurobiology of Aging, vol. 56, pp. 33-40, 2017.
[10] S. L. Rosenthal and M. I. Kamboh, "Late-onset Alzheimer's disease genes and the potentially implicated pathways," Current Genetic Medicine Reports, vol. 2, no. 2, pp. 85-101, 2014.

[11] R. B. Maccioni, J. P. Muñoz, and L. Barbeito, "The molecular bases of Alzheimer's disease and other neurodegenerative disorders," Archives of Medical Research, vol. 32, no. 5, pp. 367-381, 2001.

[12] H. W. Querfurth and F. M. LaFerla, "Alzheimer's disease," The New England Journal of Medicine, vol. 362, no. 4, pp. 329-344, 2010.

[13] P. Agostinho, A. Pliássova, C. R. Oliveira, and R. A. Cunha, "Localization and trafficking of amyloid- $\beta$ protein precursor and secretases: impact on Alzheimer's disease," Journal of Alzheimer's Disease, vol. 45, no. 2, pp. 329-347, 2015.

[14] A. Chiarini, U. Armato, E. Gardenal, L. Gui, and I. Dal Prà, "Amyloid $\beta$-exposed human astrocytes overproduce phospho-tau and overrelease it within exosomes, effects suppressed by calcilytic NPS 2143-further implications for Alzheimer's therapy," Frontiers in Neuroscience, vol. 11, 2017.

[15] C. Lindberg, M.-L. B. Selenica, A. Westlind-Danielsson, and M. Schultzberg, “ $\beta$-Amyloid protein structure determines the nature of cytokine release from rat microglia," Journal of Molecular Neuroscience, vol. 27, no. 1, pp. 1-12, 2005.

[16] L. Hou, Y. Liu, X. Wang et al., "The effects of amyloid- $\beta 42$ oligomer on the proliferation and activation of astrocytes in vitro," In Vitro Cellular \& Developmental Biology-Animal, vol. 47, no. 8, pp. 573-580, 2011.

[17] R. E. González-Reyes, M. O. Nava-Mesa, K. Vargas-Sánchez, D. Ariza-Salamanca, and L. Mora-Muñoz, "Involvement of astrocytes in Alzheimer's disease from a neuroinflammatory and oxidative stress perspective," Frontiers in Molecular Neuroscience, vol. 10, p. 427, 2017.

[18] F. M. Elahi and B. L. Miller, "A clinicopathological approach to the diagnosis of dementia," Nature Reviews Neurology, vol. 13, no. 8, pp. 457-476, 2017.

[19] N. El Kadmiri, N. Said, I. Slassi, B. El Moutawakil, and S. Nadifi, "Biomarkers for Alzheimer disease: classical and novel candidates' review," Neuroscience, vol. 370, pp. 181190, 2018.

[20] G. B. Frisoni, M. Boccardi, F. Barkhof et al., "Strategic roadmap for an early diagnosis of Alzheimer's disease based on biomarkers," The Lancet Neurology, vol. 16, no. 8, pp. 661676, 2017.

[21] L. Y. L. Chang, J. Lowe, A. Ardiles et al., “Alzheimer's disease in the human eye. Clinical tests that identify ocular and visual information processing deficit as biomarkers," Alzheimer's \& Dementia, vol. 10, no. 2, pp. 251-261, 2014.

[22] F. Z. Javaid, J. Brenton, L. Guo, and M. F. Cordeiro, "Visual and ocular manifestations of Alzheimer's disease and their use as biomarkers for diagnosis and progression," Frontiers in Neurology, vol. 7, 2016.

[23] D.-H. Lee, A. B. Laemmer, A. Waschbisch et al., "Neuromyelitis optica presenting with relapses under treatment with natalizumab: a case report," Journal of Medical Case Reports, vol. 8, no. 1, p. 155, 2014.

[24] V. Kavcic, W. Vaughn, and C. J. Duffy, "Distinct visual motion processing impairments in aging and Alzheimer's disease," Vision Research, vol. 51, no. 3, pp. 386-395, 2011.

[25] M. P. Bambo, E. Garcia-Martin, S. Otin et al., "Visual function and retinal nerve fibre layer degeneration in patients with Alzheimer disease: correlations with severity 
of dementia," Acta Ophthalmologica, vol. 93, no. 6, pp. e507-e508, 2015.

[26] C. Y.-L. Cheung, Y.-T. Ong, M. K. Ikram, C. Chen, and T. Y. Wong, "Retinal microvasculature in Alzheimer's disease," Journal of Alzheimer's Disease, vol. 42, Supplement 4, pp. S339-S352, 2014.

[27] M. K. Ikram, C. Y. Cheung, T. Y. Wong, and C. P. L. H. Chen, "Retinal pathology as biomarker for cognitive impairment and Alzheimer's disease," Journal of Neurology, Neurosurgery, and Psychiatry, vol. 83, no. 9, pp. 917-922, 2012.

[28] N. A. Arnaoutoglou, M. Arnaoutoglou, P. Nemtsas, V. Costa, S. J. Baloyannis, and K. P. Ebmeier, "Color perception differentiates Alzheimer's disease (AD) from vascular dementia (VaD) patients," International Psychogeriatrics, vol. 29, no. 8, pp. 1355-1361, 2017.

[29] C. M. Carroll and Y.-M. Li, "Physiological and pathological roles of the $\gamma$-secretase complex," Brain Research Bulletin, vol. 126, Part 2, pp. 199-206, 2016.

[30] L. J. Sosa, A. Cáceres, S. Dupraz, M. Oksdath, S. Quiroga, and A. Lorenzo, "The physiological role of the amyloid precursor protein as an adhesion molecule in the developing nervous system," Journal of Neurochemistry, vol. 143, no. 1, pp. 1129, 2017.

[31] E. Montagna, M. M. Dorostkar, and J. Herms, "The role of APP in structural spine plasticity," Frontiers in Molecular Neuroscience, vol. 10, 2017.

[32] A. T. Rao, A. J. Degnan, and L. M. Levy, "Genetics of Alzheimer disease," American Journal of Neuroradiology, vol. 35, no. 3, pp. 457-458, 2014.

[33] R. Aleksis, F. Oleskovs, K. Jaudzems, J. Pahnke, and H. Biverstål, "Structural studies of amyloid- $\beta$ peptides: unlocking the mechanism of aggregation and the associated toxicity," Biochimie, vol. 140, pp. 176-192, 2017.

[34] B. De Strooper and E. Karran, "The cellular phase of Alzheimer's disease," Cell, vol. 164, no. 4, pp. 603-615, 2016.

[35] D. Zhu, Y. Lai, P. B. Shelat, C. Hu, G. Y. Sun, and J. C.-M. Lee, "Phospholipases A2 mediate amyloid-beta peptide-induced mitochondrial dysfunction," The Journal of Neuroscience, vol. 26, no. 43, pp. 11111-11119, 2006.

[36] S. Askarova, X. Yang, W. Sheng, G. Y. Sun, and J. C.-M. Lee, "Role of $\mathrm{A} \beta$-receptor for advanced glycation endproducts interaction in oxidative stress and cytosolic phospholipase $\mathrm{A}_{2}$ activation in astrocytes and cerebral endothelial cells," Neuroscience, vol. 199, pp. 375-385, 2011.

[37] Z. Esposito, L. Belli, S. Toniolo, G. Sancesario, C. Bianconi, and A. Martorana, "Amyloid $\beta$, glutamate, excitotoxicity in Alzheimer's disease: are we on the right track?," CNS Neuroscience \& Therapeutics, vol. 19, no. 8, pp. 549-555, 2013.

[38] M. O. Nava-Mesa, L. Jiménez-Díaz, J. Yajeya, and J. D. Navarro-Lopez, "GABAergic neurotransmission and new strategies of neuromodulation to compensate synaptic dysfunction in early stages of Alzheimer's disease," Frontiers in Cellular Neuroscience, vol. 8, p. 167, 2014.

[39] L. Mosconi, S. Sorbi, M. J. de Leon et al., "Hypometabolism exceeds atrophy in presymptomatic early-onset familial Alzheimer's disease," Journal of Nuclear Medicine, vol. 47, no. 11, pp. 1778-1786, 2006.

[40] L. Mosconi, A. Pupi, and M. J. De Leon, "Brain glucose hypometabolism and oxidative stress in preclinical Alzheimer's disease," Annals of the New York Academy of Sciences, vol. 1147, no. 1, pp. 180-195, 2008.
[41] M. S. Forman, D. Lal, B. Zhang et al., "Transgenic mouse model of tau pathology in astrocytes leading to nervous system degeneration," The Journal of Neuroscience, vol. 25, no. 14, pp. 3539-3550, 2005.

[42] M. Goedert, D. S. Eisenberg, and R. A. Crowther, "Propagation of tau aggregates and neurodegeneration," Annual Review of Neuroscience, vol. 40, no. 1, pp. 189-210, 2017.

[43] J. A. Ratnayaka, L. C. Serpell, and A. J. Lotery, "Dementia of the eye: the role of amyloid beta in retinal degeneration," Eye, vol. 29, no. 8, pp. 1013-1026, 2015.

[44] T. M. Shah, S. M. Gupta, P. Chatterjee, M. Campbell, and R. N. Martins, "Beta-amyloid sequelae in the eye: a critical review on its diagnostic significance and clinical relevance in Alzheimer's disease," Molecular Psychiatry, vol. 22, no. 3, pp. 353-363, 2017.

[45] P. van Wijngaarden, X. Hadoux, M. Alwan, S. Keel, and M. Dirani, "Emerging ocular biomarkers of Alzheimer disease," Clinical \& Experimental Ophthalmology, vol. 45, no. 1, pp. 54-61, 2017.

[46] J. K. H. Lim, Q.-X. Li, Z. He et al., "The eye as a biomarker for Alzheimer's disease," Frontiers in Neuroscience, vol. 10, 2016.

[47] V. K. Gupta, N. Chitranshi, V. B. Gupta et al., "Amyloid $\beta$ accumulation and inner retinal degenerative changes in Alzheimer's disease transgenic mouse," Neuroscience Letters, vol. 623, pp. 52-56, 2016.

[48] N. J. Hart, Y. Koronyo, K. L. Black, and M. KoronyoHamaoui, "Ocular indicators of Alzheimer's: exploring disease in the retina," Acta Neuropathologica, vol. 132, no. 6, pp. 767-787, 2016.

[49] A. London, I. Benhar, and M. Schwartz, "The retina as a window to the brain-from eye research to CNS disorders," Nature Reviews Neurology, vol. 9, no. 1, pp. 44-53, 2013.

[50] Y. Kusne, A. B. Wolf, K. Townley, M. Conway, and G. A. Peyman, "Visual system manifestations of Alzheimer's disease," Acta Ophthalmologica, vol. 95, no. 8, pp. e668e676, 2017.

[51] K. Chiu, T.-F. Chan, A. Wu, I. Y.-P. Leung, K.-F. So, and R. C.-C. Chang, "Neurodegeneration of the retina in mouse models of Alzheimer's disease: what can we learn from the retina?," Age, vol. 34, no. 3, pp. 633-649, 2012.

[52] E. Vecino, F. D. Rodriguez, N. Ruzafa, X. Pereiro, and S. C. Sharma, "Glia-neuron interactions in the mammalian retina," Progress in Retinal and Eye Research, vol. 51, pp. 1-40, 2016.

[53] A. Wakx, M. Dutot, F. Massicot, F. Mascarelli, G. A. Limb, and P. Rat, "Amyloid $\beta$ peptide induces apoptosis through P2X7 cell death receptor in retinal cells: modulation by marine omega-3 fatty acid DHA and EPA," Applied Biochemistry and Biotechnology, vol. 178, no. 2, pp. 368-381, 2016.

[54] V. Dinet, J. Bruban, N. Chalour et al., "Distinct effects of inflammation on gliosis, osmohomeostasis, and vascular integrity during amyloid beta-induced retinal degeneration," Aging Cell, vol. 11, no. 4, pp. 683-693, 2012.

[55] M. M. Edwards, J. J. Rodríguez, R. Gutierrez-Lanza, J. Yates, A. Verkhratsky, and G. A. Lutty, "Retinal macroglia changes in a triple transgenic mouse model of Alzheimer's disease," Experimental Eye Research, vol. 127, pp. 252-260, 2014.

[56] G. Chidlow, J. P. M. Wood, J. Manavis, J. Finnie, and R. J. Casson, "Investigations into retinal pathology in the early stages of a mouse model of Alzheimer's disease," Journal of Alzheimer's Disease, vol. 56, no. 2, pp. 655-675, 2017. 
[57] R. T. Liu, A. Wang, E. To et al., "Vinpocetine inhibits amyloid-beta induced activation of NF- $\kappa$ B, NLRP3 inflammasome and cytokine production in retinal pigment epithelial cells," Experimental Eye Research, vol. 127, pp. 49-58, 2014.

[58] J. P. Cunha and A. Castanheira-Dinis, "Alzheimer disease: OCT retinal and choroidal thickness," in Proceedings of the 5th International Conference on Photonics, Optics and Laser Technology, Porto, Portugal, 2017.

[59] A. M. Birch, "The contribution of astrocytes to Alzheimer's disease," Biochemical Society Transactions, vol. 42, no. 5, pp. 1316-1320, 2014.

[60] C. Iadecola and M. Nedergaard, "Glial regulation of the cerebral microvasculature," Nature Neuroscience, vol. 10, no. 11, pp. 1369-1376, 2007.

[61] K. Kisler, A. R. Nelson, A. Montagne, and B. V. Zlokovic, "Cerebral blood flow regulation and neurovascular dysfunction in Alzheimer disease," Nature Reviews Neuroscience, vol. 18, no. 7, pp. 419-434, 2017.

[62] T. Iram, D. Trudler, D. Kain et al., "Astrocytes from old Alzheimer's disease mice are impaired in A $\beta$ uptake and in neuroprotection," Neurobiology of Disease, vol. 96, pp. 84-94, 2016.

[63] B. Ghebrehiwet, X. Feng, R. Kumar, and E. I. B. Peerschke, "Complement component $\mathrm{Clq}$ induces endothelial cell adhesion and spreading through a docking/signaling partnership of C1q receptors and integrins," International Immunopharmacology, vol. 3, no. 3, pp. 299-310, 2003.

[64] S. E. Perez, S. Lumayag, B. Kovacs, E. J. Mufson, and S. Xu, " $\beta$-Amyloid deposition and functional impairment in the retina of the APPswe/PS1 $\triangle \mathrm{E} 9$ transgenic mouse model of Alzheimer's disease," Investigative Ophthalmology \& Visual Science, vol. 50, no. 2, pp. 793-800, 2009.

[65] L. Y. Du, L. Y.-L. Chang, A. O. Ardiles et al., “Alzheimer's disease-related protein expression in the retina of Octodon degus," PloS One, vol. 10, no. 8, article e0135499, 2015.

[66] M. Koronyo-Hamaoui, Y. Koronyo, A. V. Ljubimov et al., "Identification of amyloid plaques in retinas from Alzheimer's patients and noninvasive in vivo optical imaging of retinal plaques in a mouse model," Neurolmage, vol. 54, Supplement 1, pp. S204-S217, 2011.

[67] Y. Tsai, B. Lu, A. V. Ljubimov et al., "Ocular changes in TgF344-AD rat model of Alzheimer's disease," Investigative Ophthalmology \& Visual Science, vol. 55, no. 1, pp. 523534, 2014.

[68] J. C. Blanks, S. Y. Schmidt, Y. Torigoe, K. V. Porrello, D. R. Hinton, and R. H. I. Blanks, "Retinal pathology in Alzheimer's disease. II. Regional neuron loss and glial changes in GCL," Neurobiology of Aging, vol. 17, no. 3, pp. 385395, 1996.

[69] C. H. Andrade-Moraes, A. V. Oliveira-Pinto, E. CastroFonseca et al., "Cell number changes in Alzheimer's disease relate to dementia, not to plaques and tangles," Brain, vol. 136, no. 12, pp. 3738-3752, 2013.

[70] G. Leuba and R. Kraftsik, "Visual cortex in Alzheimer's disease: occurrence of neuronal death and glial proliferation, and correlation with pathological hallmarks," Neurobiology of Aging, vol. 15, no. 1, pp. 29-43, 1994.

[71] V. Luibl, J. M. Isas, R. Kayed, C. G. Glabe, R. Langen, and J. Chen, "Drusen deposits associated with aging and agerelated macular degeneration contain nonfibrillar amyloid oligomers," The Journal of Clinical Investigation, vol. 116, no. 2, pp. 378-385, 2006.

[72] D. H. Anderson, R. F. Mullins, G. S. Hageman, and L. V. Johnson, "A role for local inflammation in the formation of drusen in the aging eye," American Journal of Ophthalmology, vol. 134, no. 3, pp. 411-431, 2002.

[73] A. N. Nilson, K. C. English, J. E. Gerson et al., "Tau oligomers associate with inflammation in the brain and retina of tauopathy mice and in neurodegenerative diseases," Journal of Alzheimer's Disease, vol. 55, no. 3, pp. 1083-1099, 2017.

[74] M. Chiasseu, L. Alarcon-Martinez, N. Belforte et al., "Tau accumulation in the retina promotes early neuronal dysfunction and precedes brain pathology in a mouse model of Alzheimer's disease," Molecular Neurodegeneration, vol. 12, no. 1, p. 58, 2017.

[75] W. Ho, Y. Leung, A. W. Tsang, K. F. So, K. Chiu, and R. C. Chang, "Review: Tauopathy in the retina and optic nerve: does it shadow pathological changes in the brain?," Molecular Vision, vol. 18, pp. 2700-2710, 2012.

[76] H. Zhao, R. Chang, H. Che et al., "Hyperphosphorylation of tau protein by calpain regulation in retina of Alzheimer's disease transgenic mouse," Neuroscience Letters, vol. 551, pp. 12-16, 2013.

[77] C. Schön, N. A. Hoffmann, S. M. Ochs et al., "Long-term in vivo imaging of fibrillar tau in the retina of P301S transgenic mice," PloS One, vol. 7, no. 12, article e53547, 2012.

[78] M. Rudolf, M. E. Clark, M. F. Chimento, C.-M. Li, N. E. Medeiros, and C. A. Curcio, "Prevalence and morphology of druse types in the macula and periphery of eyes with age-related maculopathy," Investigative Ophthalmology \& Visual Science, vol. 49, no. 3, pp. 1200-1209, 2008.

[79] S. McHarg, S. J. Clark, A. J. Day, and P. N. Bishop, "Age-related macular degeneration and the role of the complement system," Molecular Immunology, vol. 67, no. 1, pp. 43-50, 2015.

[80] A. I. Pogue, P. Dua, J. M. Hill, and W. J. Lukiw, "Progressive inflammatory pathology in the retina of aluminum-fed $5 x F A D$ transgenic mice," Journal of Inorganic Biochemistry, vol. 152, pp. 206-209, 2015.

[81] V. V. Ermilov and A. A. Nesterova, " $\beta$-Amyloidopathy in the pathogenesis of age-related macular degeneration in correlation with neurodegenerative diseases," Advances in Experimental Medicine and Biology, vol. 854, pp. 119-125, 2016.

[82] K. Ohno-Matsui, "Parallel findings in age-related macular degeneration and Alzheimer's disease," Progress in Retinal and Eye Research, vol. 30, no. 4, pp. 217-238, 2011.

[83] T. Yoshida, K. Ohno-Matsui, S. Ichinose et al., "The potential role of amyloid $\beta$ in the pathogenesis of age-related macular degeneration," The Journal of Clinical Investigation, vol. 115, no. 10, pp. 2793-2800, 2005.

[84] L. M. Tai, R. Thomas, F. M. Marottoli et al., "The role of APOE in cerebrovascular dysfunction," Acta Neuropathologica, vol. 131, no. 5, pp. 709-723, 2016.

[85] J.-T. Yu, L. Tan, and J. Hardy, "Apolipoprotein E in Alzheimer's disease: an update," Annual Review of Neuroscience, vol. 37, no. 1, pp. 79-100, 2014.

[86] J. Hardy and D. J. Selkoe, "The amyloid hypothesis of Alzheimer's disease: progress and problems on the road to therapeutics," Science, vol. 297, no. 5580, pp. 353-356, 2002.

[87] H. K. Dong, J.-A. Gim, S. H. Yeo, and H.-S. Kim, "Integrated late onset Alzheimer's disease (LOAD) susceptibility genes: 
cholesterol metabolism and trafficking perspectives," Gene, vol. 597, pp. 10-16, 2017.

[88] A. T. Baker-Nigh, K. G. Mawuenyega, J. G. Bollinger et al., "Human central nervous system (CNS) ApoE isoforms are increased by age, differentially altered by amyloidosis, and relative amounts reversed in the CNS compared with plasma," The Journal of Biological Chemistry, vol. 291, no. 53, pp. 27204-27218, 2016.

[89] T. Masuda, M. Shimazawa, Y. Hashimoto et al., "Apolipoprotein E2 and E3, but not E4, promote retinal pathologic neovascularization," Investigative Ophthalmology \& Visual Science, vol. 58, no. 2, pp. 1208-1217, 2017.

[90] I. Maharshak, S. Salomon-Zimri, R. Antes et al., "The effects of the apoE4 genotype on the developing mouse retina," Experimental Eye Research, vol. 145, pp. 17-25, 2016.

[91] O. Levy, S. Lavalette, S. J. Hu et al., “APOE isoforms control pathogenic subretinal inflammation in age-related macular degeneration," The Journal of Neuroscience, vol. 35, no. 40, pp. 13568-13576, 2015.

[92] J. M. Ong, N. C. Zorapapel, K. A. Rich et al., "Effects of cholesterol and apolipoprotein $\mathrm{E}$ on retinal abnormalities in ApoE-deficient mice," Investigative Ophthalmology \& Visual Science, vol. 42, no. 8, pp. 1891-1900, 2001.

[93] S. Frost, R. Guymer, K. Zaw Aung et al., "Alzheimer's disease and the early signs of age-related macular degeneration," Current Alzheimer Research, vol. 13, no. 11, pp. 12591266, 2016.

[94] M. A. Williams, V. Silvestri, D. Craig, A. P. Passmore, and G. Silvestri, "The prevalence of age-related macular degeneration in Alzheimer's disease," Journal of Alzheimer's Disease, vol. 42, no. 3, pp. 909-914, 2014.

[95] V. S. Pelak and W. Hills, "Vision in Alzheimer's disease: a focus on the anterior afferent pathway," Neurodegenerative Disease Management, vol. 8, no. 1, pp. 49-67, 2018.

[96] R. A. Armstrong, "Visual field defects in Alzheimer's disease patients may reflect differential pathology in the primary visual cortex," Optometry and Vision Science, vol. 73, no. 11, pp. 677-682, 1996.

[97] X. Liu, W. Chen, H. Hou et al., "Decreased functional connectivity between the dorsal anterior cingulate cortex and lingual gyrus in Alzheimer's disease patients with depression," Behavioural Brain Research, vol. 326, pp. 132138, 2017.

[98] A. A. Brewer and B. Barton, "Visual cortex in aging and Alzheimer's disease: changes in visual field maps and population receptive fields," Frontiers in Psychology, vol. 5, p. 74, 2014.

[99] M. Kiyosawa, T. M. Bosley, J. Chawluk et al., "Alzheimer's disease with prominent visual symptoms: clinical and metabolic evaluation," Ophthalmology, vol. 96, no. 7, pp. 10771086, 1989.

[100] R. O. Kuljis, "Lesions in the pulvinar in patients with Alzheimer's disease," Journal of Neuropathology \& Experimental Neurology, vol. 53, no. 2, pp. 202-211, 1994.

[101] D. Erskine, J. P. Taylor, M. J. Firbank et al., "Changes to the lateral geniculate nucleus in Alzheimer's disease but not dementia with Lewy bodies," Neuropathology and Applied Neurobiology, vol. 42, no. 4, pp. 366-376, 2016.

[102] R. Feng, L. Li, H. Yu, M. Liu, and W. Zhao, "Melanopsin retinal ganglion cell loss and circadian dysfunction in Alzheimer's disease (review)," Molecular Medicine Reports, vol. 13, no. 4, pp. 3397-3400, 2016.
[103] A. N. Coogan, B. Schutová, S. Husung et al., "The circadian system in Alzheimer's disease: disturbances, mechanisms, and opportunities," Biological Psychiatry, vol. 74, no. 5, pp. 333-339, 2013.

[104] L. Zhou, Q. Gao, M. Nie et al., "Degeneration and energy shortage in the suprachiasmatic nucleus underlies the circadian rhythm disturbance in ApoE-/- mice: implications for Alzheimer's disease," Scientific Reports, vol. 6, no. 1, article 36335, 2016.

[105] J. Van Erum, D. Van Dam, and P. P. De Deyn, "Sleep and Alzheimer's disease: a pivotal role for the suprachiasmatic nucleus," Sleep Medicine Reviews, vol. 40, pp. 17-27, 2018.

[106] G. Leuba and K. Saini, "Pathology of subcortical visual centres in relation to cortical degeneration in Alzheimer's disease," Neuropathology and Applied Neurobiology, vol. 21, no. 5, pp. 410-422, 1995.

[107] J. Parvizi, G. W. Van Hoesen, and A. Damasio, "The selective vulnerability of brainstem nuclei to Alzheimer's disease," Annals of Neurology, vol. 49, no. 1, pp. 53-66, 2001.

[108] F. G. Oliveira-Souza, M. L. DeRamus, T. van Groen, A. E. Lambert, M. S. Bolding, and C. E. Strang, "Retinal changes in the Tg-SwDI mouse model of Alzheimer's disease," Neuroscience, vol. 354, pp. 43-53, 2017.

[109] L. Nobili and W. G. Sannita, "Cholinergic modulation, visual function and Alzheimer's dementia," Vision Research, vol. 37, no. 24, pp. 3559-3571, 1997.

[110] A. Patricio-Martínez, L. Mendieta, I. Martínez, J. Aguilera, and I. D. Limón, "The recombinant C-terminal fragment of tetanus toxin protects against cholinotoxicity by intraseptal injection of $\beta$-amyloid peptide (25-35) in rats," Neuroscience, vol. 315 , pp. $18-30,2016$.

[111] S. H. Deibel, N. Weishaupt, A. M. Regis et al., "Subtle learning and memory impairment in an idiopathic rat model of Alzheimer's disease utilizing cholinergic depletions and $\beta$ amyloid," Brain Research, vol. 1646, pp. 12-24, 2016.

[112] R. Schliebs and T. Arendt, "The significance of the cholinergic system in the brain during aging and in Alzheimer's disease," Journal of Neural Transmission, vol. 113, no. 11, pp. 1625-1644, 2006.

[113] H. Janíčková, V. Rudajev, P. Zimčík et al., "Uncoupling of M1 muscarinic receptor/G-protein interaction by amyloid $\beta 1$ 42," Neuropharmacology, vol. 67, pp. 272-283, 2013.

[114] J. J. Dougherty, J. Wu, and R. A. Nichols, “ $\beta$-Amyloid regulation of presynaptic nicotinic receptors in rat hippocampus and neocortex," The Journal of Neuroscience, vol. 23, no. 17, pp. 6740-6747, 2003.

[115] S. Kar, D. Seto, P. Gaudreau, and R. Quirion, "Beta-amyloidrelated peptides inhibit potassium-evoked acetylcholine release from rat hippocampal slices," The Journal of Neuroscience, vol. 16, no. 3, pp. 1034-1040, 1996.

[116] J. Mayordomo-Cava, J. Yajeya, J. D. Navarro-López, and L. Jiménez-Díaz, "Amyloid- $\beta$ modulates the expression of GirK and KCNQ channel genes in the hippocampus," PLoS One, vol. 10, no. 7, article e0134385, 2015.

[117] R. N. Leão, L. V. Colom, L. Borgius, O. Kiehn, and A. Fisahn, "Medial septal dysfunction by A $\beta$-induced KCNQ channelblock in glutamatergic neurons," Neurobiology of Aging, vol. 33, no. 9, pp. 2046-2061, 2012.

[118] L. Guo, J. Duggan, and M. Cordeiro, “Alzheimer's disease and retinal neurodegeneration," Current Alzheimer Research, vol. 7, no. 1, pp. 3-14, 2010. 
[119] N. S. Foldi, R. E. C. White, and L. A. Schaefer, "Detecting effects of donepezil on visual selective attention using signal detection parameters in Alzheimer's disease," International Journal of Geriatric Psychiatry, vol. 20, no. 5, pp. 485488, 2005.

[120] M. Boucart, G. Bubbico, S. szaffarczyk et al., "Donepezil increases contrast sensitivity for the detection of objects in scenes," Behavioural Brain Research, vol. 292, pp. 443447, 2015.

[121] J. P. Cunha, N. Moura-Coelho, R. P. Proença et al., “Alzheimer's disease: a review of its visual system neuropathology. Optical coherence tomography-a potential role as a study tool in vivo," Graefe's Archive for Clinical and Experimental Ophthalmology, vol. 254, no. 11, pp. 2079-2092, 2016.

[122] M. H. Madeira, A. F. Ambrósio, and A. R. Santiago, "Glia-mediated retinal neuroinflammation as a biomarker in Alzheimer's disease," Ophthalmic Research, vol. 54, no. 4, pp. 204-211, 2015.

[123] G. Coppola, A. di Renzo, L. Ziccardi et al., "Optical coherence tomography in Alzheimer's disease: a meta-analysis," PLoS One, vol. 10, no. 8, article e0134750, 2015.

[124] S. Krantic and A. Torriglia, "Retina: source of the earliest biomarkers for Alzheimer's disease?," Journal of Alzheimer's Disease, vol. 40, no. 2, pp. 237-243, 2014.

[125] C. La Morgia, F. N. Ross-Cisneros, J. Hannibal, P. Montagna, A. A. Sadun, and V. Carelli, "Melanopsin-expressing retinal ganglion cells: implications for human diseases," Vision Research, vol. 51, no. 2, pp. 296-302, 2011.

[126] C. Laske, H. R. Sohrabi, S. M. Frost et al., "Innovative diagnostic tools for early detection of Alzheimer's disease," Alzheimer's \& Dementia, vol. 11, no. 5, pp. 561-578, 2015.

[127] C. S. Tsai, R. Ritch, B. Schwartz et al., "Optic nerve head and nerve fiber layer in Alzheimer's disease," Archives of Ophthalmology, vol. 109, no. 2, pp. 199-204, 1991.

[128] D. R. Hinton, A. A. Sadun, J. C. Blanks, and C. A. Miller, "Optic-nerve degeneration in Alzheimer's disease," New England Journal of Medicine, vol. 315, no. 8, pp. 485487, 1986.

[129] A. A. Sadun and C. J. Bassi, "Optic nerve damage in Alzheimer's disease," Ophthalmology, vol. 97, no. 1, pp. 9-17, 1990.

[130] M. P. Bambo, E. Garcia-Martin, F. Gutierrez-Ruiz et al., "Analysis of optic disk color changes in Alzheimer's disease: a potential new biomarker," Clinical Neurology and Neurosurgery, vol. 132, pp. 68-73, 2015.

[131] Y. Lu, Z. Li, X. Zhang et al., "Retinal nerve fiber layer structure abnormalities in early Alzheimer's disease: evidence in optical coherence tomography," Neuroscience Letters, vol. 480, no. 1, pp. 69-72, 2010.

[132] T. Kusbeci, O. Y. Kusbeci, N. G. Mas, H. S. Karabekir, G. Yavas, and A. Yucel, "Stereological evaluation of the optic nerve volume in Alzheimer disease," The Journal of Craniofacial Surgery, vol. 26, no. 5, pp. 1683-1686, 2015.

[133] M. A. Williams, A. J. McGowan, C. R. Cardwell et al., "Retinal microvascular network attenuation in Alzheimer's disease," Alzheimer's \& Dementia: Diagnosis, Assessment \& Disease Monitoring, vol. 1, no. 2, pp. 229-235, 2015.

[134] G. T. Feke, B. T. Hyman, R. A. Stern, and L. R. Pasquale, "Retinal blood flow in mild cognitive impairment and Alzheimer's disease," Alzheimer's \& Dementia: Diagnosis, Assessment \& Disease Monitoring, vol. 1, no. 2, pp. 144151, 2015.
[135] F. Berisha, G. T. Feke, C. L. Trempe, J. W. McMeel, and C. L. Schepens, "Retinal abnormalities in early Alzheimer's disease," Investigative Ophthalmology \& Visual Science, vol. 48, no. 5, pp. 2285-2289, 2007.

[136] S. Frost, Y. Kanagasingam, H. Sohrabi et al., "Retinal vascular biomarkers for early detection and monitoring of Alzheimer's disease," Translational Psychiatry, vol. 3, no. 2, article e233, 2013.

[137] S. M. Golzan, K. Goozee, D. Georgevsky et al., "Retinal vascular and structural changes are associated with amyloid burden in the elderly: ophthalmic biomarkers of preclinical Alzheimer's disease," Alzheimer's Research \& Therapy, vol. 9, no. 1, p. 13, 2017.

[138] M. H. Dehabadi, B. M. Davis, T. K. Wong, and M. F. Cordeiro, "Retinal manifestations of Alzheimer's disease," Neurodegenerative Disease Management, vol. 4, no. 3, pp. 241-252, 2014.

[139] R. Tzekov and M. Mullan, "Vision function abnormalities in Alzheimer disease," Survey of Ophthalmology, vol. 59, no. 4, pp. 414-433, 2014.

[140] D. Mahajan and M. Votruba, "Can the retina be used to diagnose and plot the progression of Alzheimer's disease?," Acta Ophthalmologica, vol. 95, no. 8, pp. 768-777, 2017.

[141] Y. Shao, H. Jiang, Y. Wei et al., "Visualization of focal thinning of the ganglion cell-inner plexiform layer in patients with mild cognitive impairment and Alzheimer's disease," Journal of Alzheimer's Disease, vol. 64, no. 4, pp. 1261-1273, 2018.

[142] V. Jindal, "Interconnection between brain and retinal neurodegenerations," Molecular Neurobiology, vol. 51, no. 3, pp. 885-892, 2015.

[143] S. L. Risacher, D. WuDunn, S. M. Pepin et al., "Visual contrast sensitivity in Alzheimer's disease, mild cognitive impairment, and older adults with cognitive complaints," Neurobiology of Aging, vol. 34, no. 4, pp. 1133-1144, 2013.

[144] T. J. Crawford, A. Devereaux, S. Higham, and C. Kelly, "The disengagement of visual attention in Alzheimer's disease: a longitudinal eye-tracking study," Frontiers in Aging Neuroscience, vol. 7, p. 118, 2015.

[145] G. Binetti, S. F. Cappa, E. Magni, A. Padovani, A. Bianchetti, and M. Trabucchi, "Disorders of visual and spatial perception in the early stage of Alzheimer's disease," Annals of the New York Academy of Sciences, vol. 777, no. 1, pp. 221-225, 1996.

[146] T. B. Adelstein, R. P. Kesner, and D. S. Strassberg, "Spatial recognition and spatial order memory in patients with dementia of the Alzheimer's type," Neuropsychologia, vol. 30, no. 1, pp. 59-67, 1992.

[147] M. Rizzo, S. W. Anderson, J. Dawson, R. Myers, and K. Ball, "Visual attention impairments in Alzheimer's disease," Neurology, vol. 54, no. 10, pp. 1954-1959, 2000.

[148] C. Flicker, S. H. Ferris, T. Crook, and R. T. Bartus, "Impaired facial recognition memory in aging and dementia," Alzheimer Disease and Associated Disorders, vol. 4, no. 1, pp. 4354, 1990.

[149] M. F. Mendez, M. A. Mendez, R. Martin, K. A. Smyth, and P. J. Whitehouse, "Complex visual disturbances in Alzheimer's disease," Neurology, vol. 40, no. 3, Part 1, pp. 439443, 1990.

[150] M. F. Mendez, R. J. Martin, K. A. Smyth, and P. J. Whitehouse, "Disturbances of person identification in Alzheimer's disease. A retrospective study," The Journal 
of Nervous and Mental Disease, vol. 180, no. 2, pp. 9496, 1992.

[151] A. Cronin-Golomb, S. Corkin, J. F. Rizzo, J. Cohen, J. H. Growdon, and K. S. Banks, "Visual dysfunction in Alzheimer's disease: relation to normal aging," Annals of Neurology, vol. 29, no. 1, pp. 41-52, 1991.

[152] P. R. Hof and C. Bouras, "Object recognition deficit in Alzheimer's disease: possible disconnection of the occipitotemporal component of the visual system," Neuroscience Letters, vol. 122, no. 1, pp. 53-56, 1991.

[153] P. R. Hof, C. Bouras, J. Constantinidis, and J. H. Morrison, "Selective disconnection of specific visual association pathways in cases of Alzheimer's disease presenting with Balint's syndrome," Journal of Neuropathology and Experimental Neurology, vol. 49, no. 2, pp. 168-184, 1990.

[154] P.-F. Kaeser, J. Ghika, and F.-X. Borruat, "Visual signs and symptoms in patients with the visual variant of Alzheimer disease," BMC Ophthalmology, vol. 15, no. 1, p. 65, 2015.

[155] R. Armstrong and A. Syed, "Alzheimer's disease and the eye," Ophthalmic and Physiological Optics, vol. 16, pp. S2-S8, 1996.

[156] V. Polo, M. J. Rodrigo, E. Garcia-Martin et al., "Visual dysfunction and its correlation with retinal changes in patients with Alzheimer's disease," Eye, vol. 31, no. 7, pp. 10341041, 2017.

[157] S. A. Neargarder, E. R. Stone, A. Cronin-Golomb, and S. Oross, "The impact of acuity on performance of four clinical measures of contrast sensitivity in Alzheimer's disease," The Journals of Gerontology Series B: Psychological Sciences and Social Sciences, vol. 58, no. 1, pp. P54-P62, 2003.

[158] F. Sartucci, D. Borghetti, T. Bocci et al., "Dysfunction of the magnocellular stream in Alzheimer's disease evaluated by pattern electroretinograms and visual evoked potentials," Brain Research Bulletin, vol. 82, no. 3-4, pp. 169176,2010

[159] G. Salamone, C. di Lorenzo, S. Mosti et al., "Color discrimination performance in patients with Alzheimer's disease," Dementia and Geriatric Cognitive Disorders, vol. 27, no. 6, pp. 501-507, 2009.

[160] R. Prettyman, P. Bitsios, and E. Szabadi, "Altered pupillary size and darkness and light reflexes in Alzheimer's disease," Journal of Neurology, Neurosurgery, and Psychiatry, vol. 62, no. 6, pp. 665-668, 1997.

[161] R. J. Molitor, P. C. Ko, and B. A. Ally, "Eye movements in Alzheimer's disease," Journal of Alzheimer's Disease, vol. 44, no. 1, pp. 1-12, 2015.

[162] W. A. Fletcher and J. A. Sharpe, "Saccadic eye movement dysfunction in Alzheimer's disease," Annals of Neurology, vol. 20, no. 4, pp. 464-471, 1986.

[163] O. A. Coubard, "What do we know about eye movements in Alzheimer's disease? The past 37 years and future directions," Biomarkers in Medicine, vol. 10, no. 7, pp. 677-680, 2016.

[164] C.-N. Lee and K.-W. Park, "Cognitive functions and stereopsis in patients with parkinson's disease and Alzheimer's disease," Alzheimer's \& Dementia, vol. 10, no. 4, article P767, 2014.

[165] H. Kergoat, M. J. Kergoat, L. Justino, H. Chertkow, A. Robillard, and H. Bergman, "An evaluation of the retinal nerve fiber layer thickness by scanning laser polarimetry in individuals with dementia of the Alzheimer type," Acta Ophthalmologica Scandinavica, vol. 79, no. 2, pp. 187191, 2001.
[166] S. Kirbas, K. Turkyilmaz, O. Anlar, A. Tufekci, and M. Durmus, "Retinal nerve fiber layer thickness in patients with Alzheimer disease," Journal of Neuro-Ophthalmology, vol. 33, no. 1, pp. 58-61, 2013.

[167] A. Trebbastoni, F. D’Antonio, A. Bruscolini et al., "Retinal nerve fibre layer thickness changes in Alzheimer's disease: results from a 12-month prospective case series," Neuroscience Letters, vol. 629, pp. 165-170, 2016.

[168] E. Garcia-Martin, M. P. Bambo, M. L. Marques et al., "Ganglion cell layer measurements correlate with disease severity in patients with Alzheimer's disease," Acta Ophthalmologica, vol. 94, no. 6, pp. e454-e459, 2016.

[169] D. Liu, L. Zhang, Z. Li et al., "Thinner changes of the retinal nerve fiber layer in patients with mild cognitive impairment and Alzheimer's disease," BMC Neurology, vol. 15, no. 1, p. 14, 2015.

[170] A. Kesler, V. Vakhapova, A. D. Korczyn, E. Naftaliev, and M. Neudorfer, "Retinal thickness in patients with mild cognitive impairment and Alzheimer's disease," Clinical Neurology and Neurosurgery, vol. 113, no. 7, pp. 523526, 2011.

[171] C. Paquet, M. Boissonnot, F. Roger, P. Dighiero, R. Gil, and J. Hugon, "Abnormal retinal thickness in patients with mild cognitive impairment and Alzheimer's disease," Neuroscience Letters, vol. 420, no. 2, pp. 97-99, 2007.

[172] P. J. Snyder, L. N. Johnson, Y. Y. Lim et al., "Nonvascular retinal imaging markers of preclinical Alzheimer's disease," Alzheimer's \& Dementia: Diagnosis, Assessment \& Disease Monitoring, vol. 4, pp. 169-178, 2016.

[173] H. A. Bayhan, S. Aslan Bayhan, A. Celikbilek, N. Tanık, and C. Gürdal, "Evaluation of the chorioretinal thickness changes in Alzheimer's disease using spectral-domain optical coherence tomography," Clinical \& Experimental Ophthalmology, vol. 43, no. 2, pp. 145-151, 2015.

[174] F. J. Ascaso, N. Cruz, P. J. Modrego et al., "Retinal alterations in mild cognitive impairment and Alzheimer's disease: an optical coherence tomography study," Journal of Neurology, vol. 261, no. 8, pp. 1522-1530, 2014

[175] D. Rodriguez-Mena, C. Almarcegui, I. Dolz, L. E. Pablo, and E. Garcia-Martin, "Application of electrophysiological tests in the study of neurological diseases with visual involvement," Archivos De La Sociedad Espanola De Oftalmologia, vol. 87, no. 10, pp. 311-314, 2012.

[176] S. H. Choi, S. J. Park, and N. R. Kim, "Macular ganglion cell -inner plexiform layer thickness is associated with clinical progression in mild cognitive impairment and Alzheimers disease," PLoS One, vol. 11, no. 9, article e0162202, 2016.

[177] E. O. Oktem, E. Derle, S. Kibaroglu, C. Oktem, I. Akkoyun, and U. Can, "The relationship between the degree of cognitive impairment and retinal nerve fiber layer thickness," Neurological Sciences, vol. 36, no. 7, pp. 1141-1146, 2015.

[178] L. Gao, Y. Liu, X. Li, Q. Bai, and P. Liu, “Abnormal retinal nerve fiber layer thickness and macula lutea in patients with mild cognitive impairment and Alzheimer's disease," Archives of Gerontology and Geriatrics, vol. 60, no. 1, pp. 162-167, 2015.

[179] E. Salobrar-Garcia, I. Hoyas, M. Leal et al., "Analysis of retinal peripapillary segmentation in early Alzheimer's disease patients," BioMed Research International, vol. 2015, Article ID 636548, 8 pages, 2015. 
[180] J. den Haan, F. D. Verbraak, P. J. Visser, and F. H. Bouwman, "Retinal thickness in Alzheimer's disease: a systematic review and meta-analysis," Alzheimer's \& Dementia: Diagnosis, Assessment \& Disease Monitoring, vol. 6, pp. 162-170, 2017.

[181] L. P. Cunha, L. C. Lopes, L. V. F. Costa-Cunha et al., "Macular thickness measurements with frequency domain-OCT for quantification of retinal neural loss and its correlation with cognitive impairment in Alzheimer's disease," PLoS One, vol. 11, no. 4, article e0153830, 2016.

[182] J. P. Cunha, R. Proença, A. Dias-Santos et al., "Choroidal thinning: Alzheimer's disease and aging," Alzheimer's \& Dementia : Diagnosis, Assessment \& Disease Monitoring, vol. 8, pp. 11-17, 2017.

[183] A. Trebbastoni, M. Marcelli, F. Mallone et al., "Attenuation of choroidal thickness in patients with Alzheimer disease: evidence from an Italian prospective study," Alzheimer Disease and Associated Disorders, vol. 31, no. 2, pp. 128134, 2017.

[184] V. E. Pollock, L. S. Schneider, H. C. Chui, V. Henderson, M. Zemansky, and R. B. Sloane, "Visual evoked potentials in dementia: a meta-analysis and empirical study of Alzheimer's disease patients," Biological Psychiatry, vol. 25, no. 8, pp. 1003-1013, 1989.

[185] S. Holroyd and M. L. Shepherd, “Alzheimer's disease: a review for the ophthalmologist," Survey of Ophthalmology, vol. 45, no. 6, pp. 516-524, 2001.

[186] B. Katz and S. Rimmer, "Ophthalmologic manifestations of Alzheimer's disease," Survey of Ophthalmology, vol. 34, no. 1, pp. 31-43, 1989.

[187] R. Kromer, N. Serbecic, L. Hausner, L. Froelich, and S. C. Beutelspacher, "Comparison of visual evoked potentials and retinal nerve fiber layer thickness in Alzheimer's disease," Frontiers in Neurology, vol. 4, 2013.

[188] P. K. Iseri, Ö. Altinaş, T. Tokay, and N. Yüksel, "Relationship between cognitive impairment and retinal morphological and visual functional abnormalities in Alzheimer disease," Journal of Neuro-Ophthalmology, vol. 26, no. 1, pp. 1824, 2006

[189] V. Parisi, R. Restuccia, F. Fattapposta, C. Mina, M. G. Bucci, and F. Pierelli, "Morphological and functional retinal impairment in Alzheimer's disease patients," Clinical Neurophysiology, vol. 112, no. 10, pp. 1860-1867, 2001.

[190] K. Krasodomska, W. Lubiński, A. Potemkowski, and K. Honczarenko, "Pattern electroretinogram (PERG) and pattern visual evoked potential (PVEP) in the early stages of Alzheimer's disease," Documenta Ophthalmologica, vol. 121, no. 2, pp. 111-121, 2010.

[191] H. Kergoat, M.-J. Kergoat, L. Justino, H. Chertkow, A. Robillard, and H. Bergman, "Visual retinocortical function in dementia of the Alzheimer type," Gerontology, vol. 48, no. 4, pp. 197-203, 2002.

[192] B. Katz, S. Rimmer, V. Iragui, and R. Katzman, "Abnormal pattern electroretinogram in Alzheimer's disease: evidence for retinal ganglion cell degeneration?," Annals of Neurology, vol. 26, no. 2, pp. 221-225, 1989.

[193] G. L. Trick, M. C. Barris, and M. Bickler-Bluth, "Abnormal pattern electroretinograms in patients with senile dementia of the Alzheimer type," Annals of Neurology, vol. 26, no. 2, pp. 226-231, 1989.

[194] L. Justino, M. J. Kergoat, H. Bergman, H. Chertkow, A. Robillard, and H. Kergoat, "Neuroretinal function is normal in early dementia of the Alzheimer type," Neurobiology of Aging, vol. 22, no. 4, pp. 691-695, 2001.

[195] F. Altimiras, B. Uszczynska-Ratajczak, F. Camara et al., "Brain transcriptome sequencing of a natural model of Alzheimer's disease," Frontiers in Aging Neuroscience, vol. 9, 2017.

[196] X.-F. He, Y.-T. Liu, C. Peng, F. Zhang, S. Zhuang, and J.-S. Zhang, "Optical coherence tomography assessed retinal nerve fiber layer thickness in patients with Alzheimer's disease: a meta-analysis," International Journal of Ophthalmology, vol. 5, no. 3, pp. 401-405, 2012.

[197] B. J. Kim, D. J. Irwin, D. Song et al., "Optical coherence tomography identifies outer retina thinning in frontotemporal degeneration," Neurology, vol. 89, no. 15, pp. 16041611, 2017.

[198] E. A. Williams, D. McGuone, M. P. Frosch, B. T. Hyman, N. Laver, and A. Stemmer-Rachamimov, "Absence of Alzheimer disease neuropathologic changes in eyes of subjects with Alzheimer disease," Journal of Neuropathology and Experimental Neurology, vol. 76, no. 5, pp. 376383, 2017.

[199] T. Tian, B. Zhang, Y. Jia, and Z. Li, "Promise and challenge: the lens model as a biomarker for early diagnosis of Alzheimer's disease," Disease Markers, vol. 2014, Article ID 826503, 5 pages, 2014.

[200] L. Bei, Y.-B. Shui, F. Bai, S. K. Nelson, G. P. Van Stavern, and D. C. Beebe, "A test of lens opacity as an indicator of preclinical Alzheimer disease," Experimental Eye Research, vol. 140, pp. 117-123, 2015.

[201] C. Y.-L. Cheung, Y. T. Ong, M. K. Ikram et al., "Microvascular network alterations in the retina of patients with Alzheimer's disease," Alzheimer's \& Dementia: The Journal of the Alzheimer's Association, vol. 10, no. 2, pp. 135-142, 2014.

[202] G. Banerjee, R. Carare, C. Cordonnier et al., "The increasing impact of cerebral amyloid angiopathy: essential new insights for clinical practice," Journal of Neurology, Neurosurgery, and Psychiatry, vol. 88, no. 11, pp. 982-994, 2017.

[203] S. McGrory, J. R. Cameron, E. Pellegrini et al., "The application of retinal fundus camera imaging in dementia: a systematic review," Alzheimer's \& Dementia: Diagnosis, Assessment \& Disease Monitoring, vol. 6, pp. 91-107, 2017.

[204] C.-Y. Ho, J. C. Troncoso, D. Knox, W. Stark, and C. G. Eberhart, "Beta-amyloid, phospho-tau and alpha-synuclein deposits similar to those in the brain are not identified in the eyes of Alzheimer's and Parkinson's disease patients," Brain Pathology, vol. 24, no. 1, pp. 25-32, 2014.

[205] A. B. Syed, R. A. Armstrong, and C. U. Smith, "A quantitative analysis of optic nerve axons in elderly control subjects and patients with Alzheimer's disease," Folia Neuropathologica, vol. 43, no. 1, pp. 1-6, 2005.

[206] C. A. Curcio and D. N. Drucker, "Retinal ganglion cells in Alzheimer's disease and aging," Annals of Neurology, vol. 33, no. 3, pp. 248-257, 1993.

[207] J. C. Blanks, Y. Torigoe, D. R. Hinton, and R. H. I. Blanks, "Retinal degeneration in the macula of patients with Alzheimer's disease," Annals of the New York Academy of Sciences, vol. 640, no. 1, pp. 44-46, 1991.

[208] J. C. Blanks, D. R. Hinton, A. A. Sadun, and C. A. Miller, "Retinal ganglion cell degeneration in Alzheimer's disease," Brain Research, vol. 501, no. 2, pp. 364-372, 1989. 
[209] S. Joly, S. Lamoureux, and V. Pernet, "Nonamyloidogenic processing of amyloid beta precursor protein is associated with retinal function improvement in aging male $\mathrm{APP}_{\text {swe }}$ / PS1 $\mathrm{E} 9$ mice," Neurobiology of Aging, vol. 53, pp. 181191, 2017.

[210] P. A. Williams, R. A. Thirgood, H. Oliphant et al., "Retinal ganglion cell dendritic degeneration in a mouse model of Alzheimer's disease," Neurobiology of Aging, vol. 34, no. 7, pp. 1799-1806, 2013. 


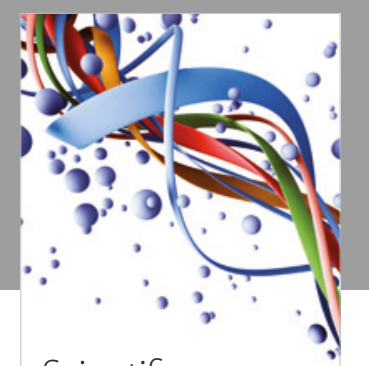

Scientifica
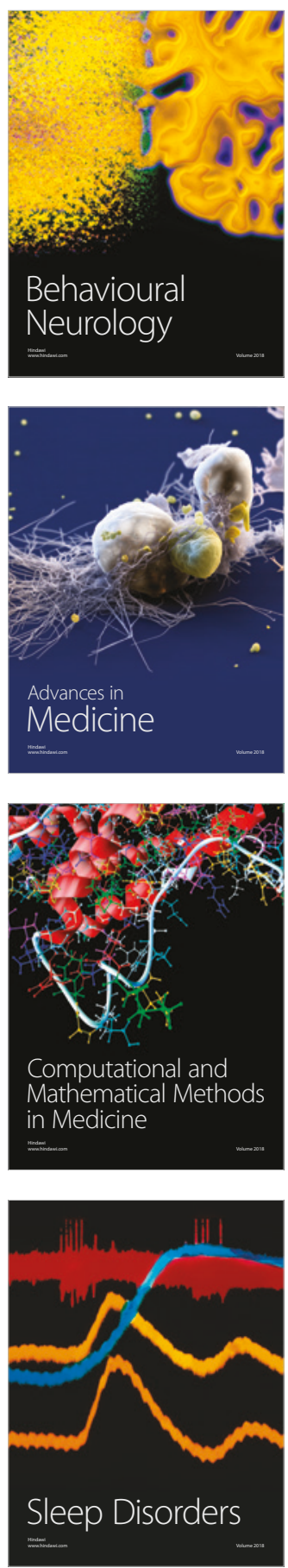

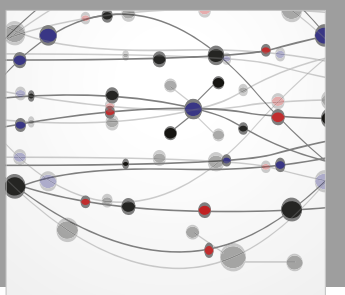

The Scientific World Journal

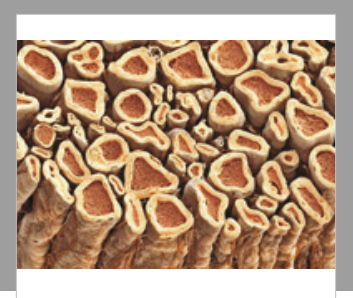

Case Reports in

Neurological Medicine

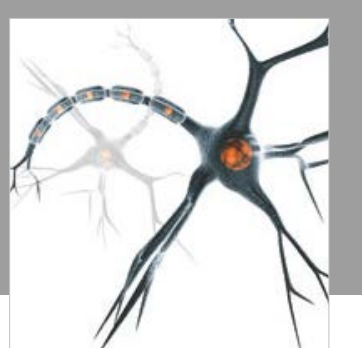

Neural Plasticity

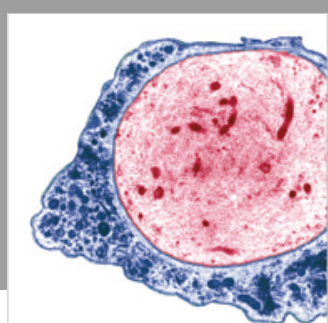

Multiple Sclerosis

International

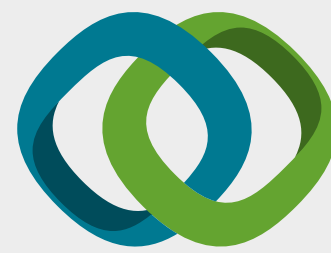

Hindawi

Submit your manuscripts at

www.hindawi.com
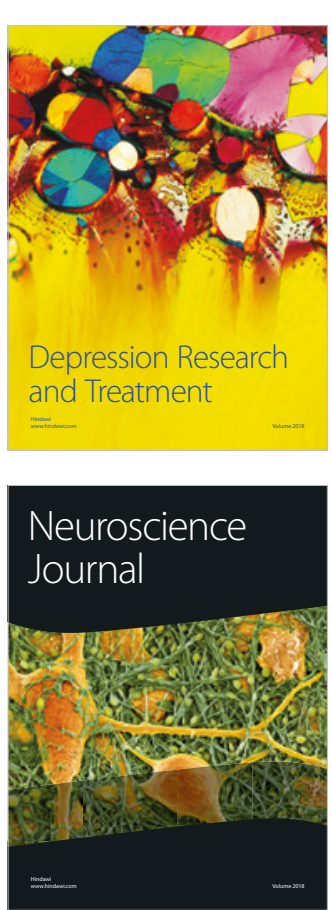

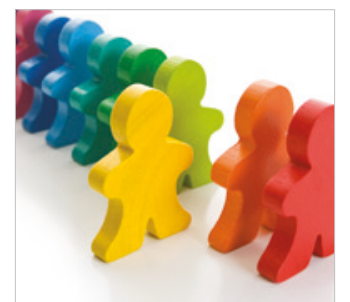

Autism

Research and Treatment
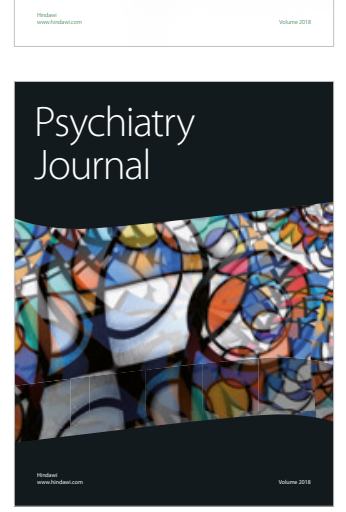
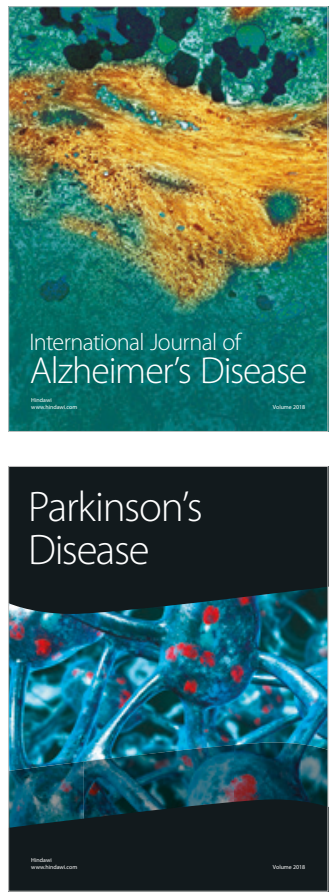
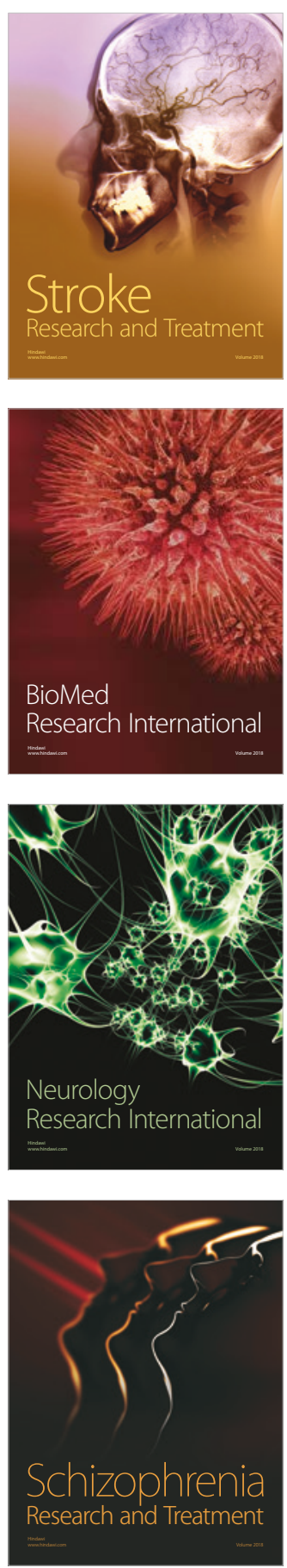